\title{
Drought episodes in the Czech Republic and their potential effects in agriculture
}

\author{
Vera Potop • Luboš Türkott • Věra Kožnarová • \\ Martin Možný
}

Received: 4 July 2008 / Accepted: 23 April 2009/Published online: 15 May 2009

(C) The Author(s) 2009. This article is published with open access at Springerlink.com

\begin{abstract}
This paper presents the methodology for assessment of drought episodes and their potential effects on winter and spring cereal crops in the Czech Republic (in the text referred to as Czechia). Historical climate and crop yields data for the period of 47 years (1961-2007) have been integrated into an agrometeorological database. The drought episodes were determined by three methods: according to the values of the standardized precipitation index (SPI), percentage of long-term precipitations $(r)$, and on the basis of the Ped drought index $\left(S_{\mathrm{i}}\right)$. Consequently, the combined SPI, $S_{\mathrm{i}}$, and $r$ indices have been used as tools in identification of the severity, frequency, and extent of drought episodes. Additionally, the paper also presents the $S_{\mathrm{i}}$ drought index and its potential use for real-time monitoring of spatial extension and severity of droughts in Czechia. The drought risk to crops was analyzed by identifying the relationships between the fluctuation of crop yields and drought index $\left(S_{\mathrm{i}}\right)$ based on the multiple regression analysis with stepwise selection. In general, models explain that a high percentage of the variability of the yield is due to drought (more than $45 \%$ of yield variance).
\end{abstract}

V. Potop $(\bowtie) \cdot$ L. Türkott $\cdot$ V. Kožnarová

Faculty of Agrobiology, Food and Natural Resources,

Department of Agroecology and Biometeorology,

Czech University of Life Sciences Prague,

Kamýcká 129, Suchdol,

1650021 Prague, Czech Republic

e-mail: potop@af.czu.cz

M. Možný

Agrometeorological Observatory in Doksany,

Czech Hydrometeorological Institute,

41182 Doksany, Czech Republic

\section{Introduction}

The occurrence of extreme drought events has always led to a number of subsequent studies. The recent European severe droughts (e.g., 2003 in central Europe, 2005 in the Iberian Peninsula and in 2007 almost throughout Europe) have emphasized that the impact on European economies can be significant. Various studies concluded that in recent decades the drought situation in many European regions and throughout the world had become more severe due to climate change (e.g., van Lanen and Peters 2000; LloydHughes and Saunders 2002; Rossi et al. 2003). This tendency has been recorded in the twentieth century, particularly in its last decade (1990-2000), which was the warmest of the century. Climate change predictions for Europe indicate considerable changes in the water balance throughout Europe, with an increased probability for summer droughts in the Mediterranean, South Eastern, and also Central Europe, including the territory of the Czech Republic (IPCC 2007). A growing number of studies is focusing on the drought risk and vulnerability assessment (e.g., Lana and Burgueño 1998; Wilhelmi et al. 2002; Brunetti et al. 2002; Heim 2002; Wilhite 2000), drought monitoring and early warming (Wilhite and Svoboda 2000; Svoboda et al. 2002), and drought policy and mitigation activities (Liu and Kogan 1996; Kogan 2000; Sonnett et al. 2006; Brown et al. 2008).

Effects of drought are dependent not only on the duration, intensity, and areas affected by a drought episode and water supplies but also on the level of economic development in a given country (Wilhite 1990). Therefore, the consequences of droughts of identical intensities and durations will have different effects in different regions. As an example, in 2007, a severe drought occurred, which was much more pronounced in the South-East Europe, in 
countries such as Romania, Bulgaria, and Moldova, than elsewhere. As a result, the drought in Moldova, which considerably reduced yields of winter crops (mostly wheat and barley, which were down by $40 \%$ and $55 \%$, respectively) and summer crops (sunflower, maize, grapes, etc.), affected the overall agricultural production and drastically reduced returns on leased land and on labor to the majority of small holders, who usually receive in-kind payments of wheat, corn, and oil (FAO 2007). At the same time, a severe spring drought was registered across Czechia, which started as a consequence of poor winter snowfalls and little spring rain. Then, during April of 2007, the drought affected 96\% of the territory of Czechia (Potop et al. 2008). Firstly, due to the fact that the drought in the Czech Republic had not occurred during the reproductive phase of the crops, the yields were not drastically affected. Secondly, different effects of the drought in Moldova and Czechia are associated with different levels of development of agriculture and climate conditions in the two countries.

In respect to the studies of the drought episodes pattern in the Czech Republic, over the past decade, many climatologists have studied the frequency and intensity of this event (Dubrovsky et al. 2000, 2008; Trnka et al. 2008; Brazdil et al. 2003) and the relationships between agriculture and crops (Trnka et al. 2007). A group of Czech climatologists (Brazdil et al. 2008) basing their study on both $Z$ index and PDSI indices have concluded that droughts in Czechia have an increasing tendency toward longer and more intensive dry episodes in which, for example, droughts that occurred in the mid-1930s, late 1940 s to early 1950 s, late 1980 s to early 1990 s, and early 2000s were the most severe.

The predominant drought indices usually used to establish drought conditions in the Czech Republic are SPI, PDSI, Palmer's $Z$ index, and Lang's rain factor. The last mentioned index, i.e., Lang's rain factor, is one of the oldest and most frequently used indices for the identification of dry and/or wet areas, which is also the most popular in the Czech Republic (Tolasz et al. 2007). Its popularity is mainly due to its simplicity, which is based on the ratio of the average annual precipitation total to the average annual air temperature. At the same time, both indices, PDSI and $Z$ index, have become two of the most widely used tools for the drought assessment in Czechia. However, the main obstacle in implementing these indices is a lack of input of meteorological information about the amount of moisture in the soil from the majority of the weather stations in the country's network. Since the calculations of the indices values are based on data from a very small number of stations, their indices have not been used in this paper. Instead, input data from about 600 ombrometric stations within the territory of Czechia can be used for the calculation of the SPI value. As a result, meteorological variables are a primary source responsible for the assessment of the drought effect and are considered a key element in defining a drought and deciding on the techniques for its analysis. The determinant variable for the meteorological drought is rainfall, whereas for agricultural drought, it is soil moisture. Thus, drought indices describe the severity of drought as compared to the long-term average or normal condition and are usually calculated from one or more of the following variables: rainfall, temperature, soil water holding capacity, and other water supply indicators (Hayes 2003; Keyantash and Dracup 2002).

This study of drought brings important theoretical contributions since it allows a more detailed and causal knowledge of this event and of its role in the characterization of the climate of the territory of the Czech Republic. At present, agriculture and water management sectors in Czechia are highly vulnerable to drought events. Increasing severity of droughts may bring on undesirable effects such as decreased water resource quantity and quality and decreased crop yields. While the drought events have been studied extensively, there is limited discussion of the effects of drought on the variation in individual crop's yields. Yields of crops in the long term are a result of the interaction of a farmer's skill and technical equipment with usual environmental conditions of sites. The actual yield and quality are affected by the occurrence of biotic and abiotic stresses within a given year governed by the course of the weather (Craufurd and Oeacock 1993; Calderini and Slafer 1998; Chloupek et al. 2004; Claassen and Shaw 1970). The second part of this study shows a complex analysis of droughts and their impact on the fluctuations in the yields of cereal crops. Drought risk is considered to have potentially adverse effects on the regional production level of cereal crops yields. The major aspects of drought that increase or decrease its adverse effects are the frequency, severity, and the spatial extent. A risk assessment framework utilizes the historical climate and crop yield data to characterize and quantify the impact of drought (Unganai and Kogan 1998; Wilhelmi et al. 2002). The methods have certain advantages such as having simple processes and easily available data and providing quantitative and comparative analysis results. The methodology employed in this paper can be applied to the study of other agrometeorological risks. Information from this study provides a potentially useful reference in the decision making concerning the drought disaster prevention and agricultural sustainable development planning.

The first and main aim of this paper is to propose the usage of more indicators and characteristics for the detection of a drought episode: the number of drought months in a warm period, percentage of weather stations, which had detected drought, departures of the regional yield $\left(y_{i}^{(T)}\right)$ of individual cereal crops, and the $S_{\mathrm{i}}$, SPI, and 


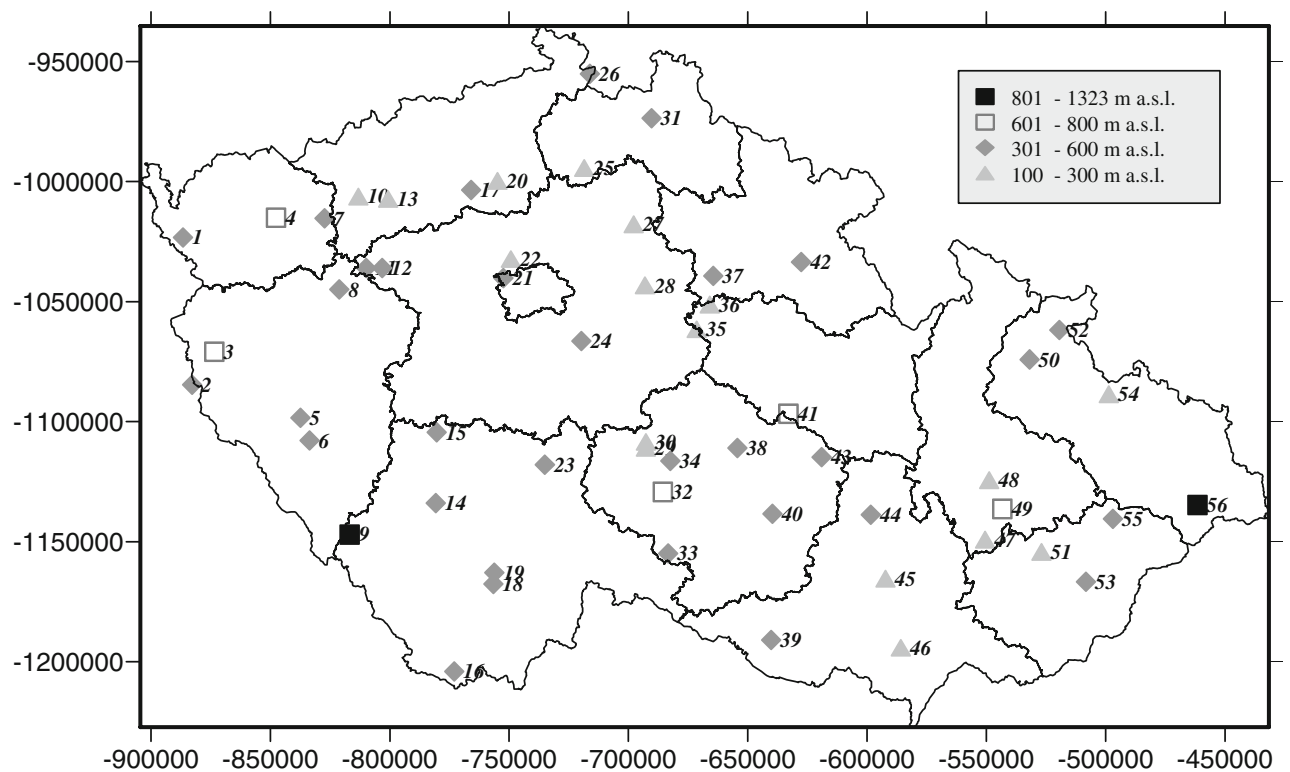

Fig. 1 Map of location of the 56 stations used for the calculation of drought indices in Czechia. The coordinate S-JTSK Krovak EastNorth system was applied for creating the maps

$r$ indices. The second aim is to present the $S_{\mathrm{i}}$ drought index and its potential use for real time monitoring of spatial extension and severity of droughts in Czechia.

\section{Materials and methods}

\subsection{Station climate database and regions crop yields}

This paper has integrated historical climate and yield data obtained from the agrometeorological database. The weather data basis has included the monthly precipitation amounts $(\mathrm{mm})$ and monthly average air temperatures $\left({ }^{\circ} \mathrm{C}\right)$. For the 56 climatological stations, which are uniformly distributed across the country, the statistical sequence covers the interval from 1961 to the present (Fig. 1). The data series was homogenized and checked at the climatology section at the Czech Hydrometeorological Institute. In addition, the monthly soil moisture measurements under grass cover in the 0-40-cm layer from 1961 to 2007 (AprilSeptember) have been used. Values are expressed in percentage of available water capacity of soil. The agrodatabases contain yearly region-level logs of winter and spring cultures of cereal yields as reported by the Czech Statistical Office. The regions are displayed in Fig. 1. The original yields dataset available for 46 years (1961-2006) is included: spring wheat, winter wheat, spring barley, winter barley, winter rye, oats, and maize (Table 1).

\subsection{Methods}

Drought effect on cereal crops Comparing the regional yields of crops and the national yields of crops, one can state that the yields were comparable or higher, particularly in maize and winter wheat. As Fig. 2 indicates, the fastest yield growth was found in maize and wheat $(+4.6$ and $+2.3 \mathrm{t} / \mathrm{ha})$ and spring barley and winter barley $(+2.2 \mathrm{t} / \mathrm{ha})$, while slower growth was found for oats and winter rye $(+0.7$
Table 1 Departures of annual yield $(\sigma)$ calculated for individual crops (1961-2006)

\begin{tabular}{lllll}
\hline Crops & \multicolumn{4}{l}{ Three levels of departures, $y_{i}^{(T)}$} \\
\cline { 3 - 5 } & & $-0.5 \sigma \geq y_{i}^{(T)}>-\sigma$ & $-\sigma \geq y_{i}^{(T)}>-1.5 \sigma$ & $y_{i}^{(T)} \leq-1.5 \sigma$ \\
\hline Triticum aestivum L. & Winter wheat & -0.06 to -0.11 & -0.12 to -0.17 & $\leq-0.18$ \\
Triticum aestivum L. & Spring wheat & -0.06 to -0.11 & -0.12 to -0.17 & $\leq-0.18$ \\
Hordeum vulgare L. & Winter barley & -0.09 to -0.17 & -0.18 to -0.26 & $\leq-0.27$ \\
Hordeum vulgare L. & Spring barley & -0.09 to -0.17 & -0.18 to -0.26 & $\leq-0.27$ \\
Secale cereale L. & Winter rye & -0.06 to -0.11 & -0.12 to -0.17 & $\leq-0.18$ \\
Avena sativa L. & Oats & -0.08 to -0.15 & -0.16 to -0.23 & $\leq-0.24$ \\
Zea mays L. & Maize & -0.09 to -0.17 & -0.18 to -0.26 & $\leq-0.27$ \\
\hline
\end{tabular}


Fig. 2 Quadratic trends of annual average yields ( $t / h a)$ for spring and winter crops in the Czech Republic (1961-2006)

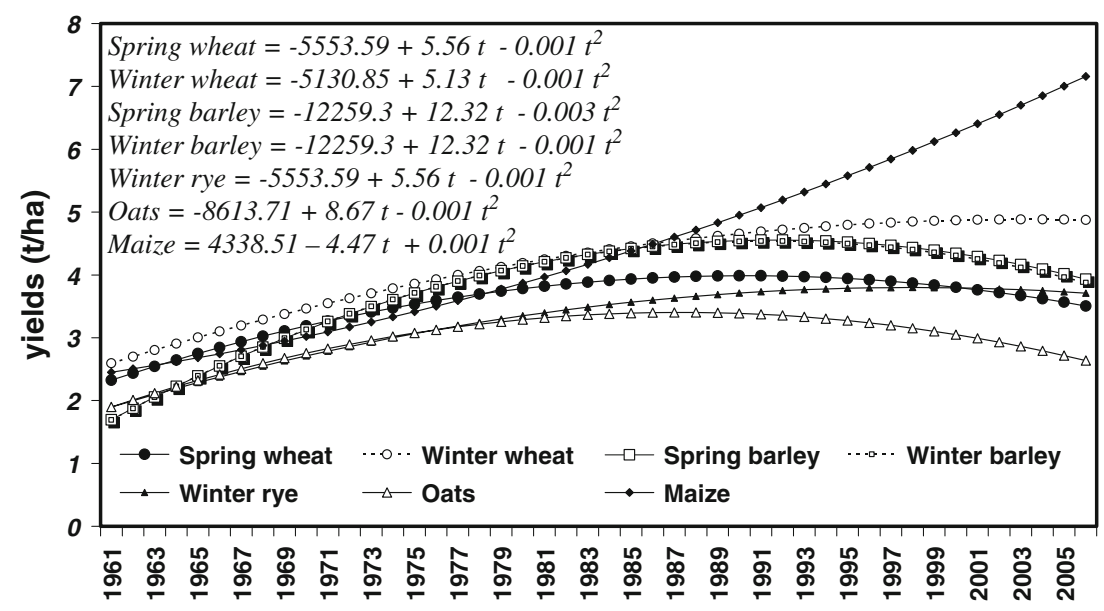

and $+1.8 \mathrm{t} / \mathrm{ha}$ ). The indicator of agricultural drought risk can be represented by the residuals of the yield. In this study, the fluctuations in crop yields over time were calculated on the basis of two components. The first one is determined by the agricultural technology level and/or the climatic conditions, and the second one is based on the agrometeorological conditions during the growing season from 1 year to the next (Fig. 3):

$\mathrm{Cm}=y_{i}^{(\tau)}+y_{i}^{(T)}$

where $y_{i}^{(\tau)}$ yield is presented by a dynamically mean value (influenced by long-term factors such as cultivation technique and standard management), and $y_{i}^{(T)}$ anomaly of yield was represented by the residuals of the detrended yield because the residual variation reflects the best effects of the weather on the yield. Thus, the response of yield is dependent on the meteorological conditions during the growing season as well as during the preceding periods.
Technological progress and improvement of societal conditions are responsible for the generally increasing trend of the crop yield. Using the weather-yield model as a measure of the fluctuations in crop yields, it is possible to reflect the changes in the favorable and unfavorable agrometeorological conditions and their impacts on the crop production every year (Wu and Wilhite 2004). Thus, the interannual departures of the regional yield $y_{i}^{(T)}$ of individual cereal plants can be expressed as follows:

$y_{i}^{(T)}=y_{i}^{O}-y_{i}^{(\tau)}$

where $y_{i}^{O}$ is the observed crop yield, and $y_{i}^{(\tau)}$ is the value of the trend in a separate year. The significant negative departures were assumed to be primarily an effect of a drought event. The assumption that in years when the real yield $y_{i}^{O}$ was bigger than the mean dynamical value $y_{i}^{(\tau)}$, agrometeorological condition was favorable during the growing season $y_{i}^{\mathrm{O}}>y_{i}^{(\tau)}$. The years in which the real
Fig. 3 The evident annual variability of $\mathrm{Cm}$ index for spring wheat, winter wheat, spring barley, winter barley, winter rye, oats, and maize

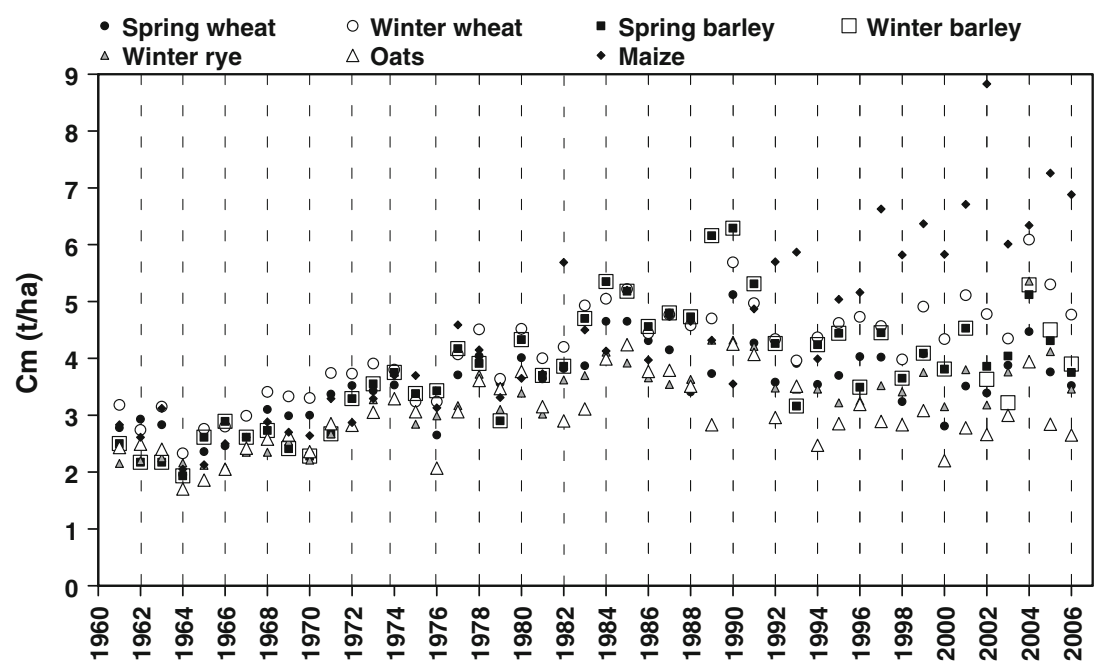


yield $y_{i}^{O}$ was smaller than the mean dynamical value $y_{i}^{O}<y_{i}^{(\tau)}$, agrometeorological condition was considered unfavorable. Thus, the response of yield is dependent on the meteorological conditions during the growing season as well as during the preceding periods.

In agreement with the developed model, the drought effect associated with the yield is smaller than $y_{i}^{(T)} \leq-0.5 \sigma$. The year with a drought risk was identified by the cereals of detrended yield: low-drought risk $-0.5 \sigma \geq y_{i}^{(T)}>-\sigma$, a middle-drought risk is $-\sigma \geq y_{i}^{(T)}>-1.5 \sigma$, and $y_{i}^{(T)} \leq-1.5 \sigma$ is a high-drought risk.

Drought indices The effect of drought on cereal crops production depends on the duration, time of occurrence, and severity (as expressed by drought indices $S_{\mathrm{i}}$, SPI, and $r$ ). The $S_{\mathrm{i}}$ combines the effects of temperature and precipitation in drought monitoring, while the SPI and $r$ are based solely on the precipitation data. Also, the SPI is used for detecting the early inception and end of drought, although it is being widely used to detect the early emergence of drought in Czechia and many other countries (e.g., Agnew 2000; Vicente-Serrano and Cuadrat-Prats 2007; Livada and Assimakopoulos 2007; Loukas and Vasiliades 2004). Therefore, the combination of the SPI, $S_{\mathrm{i}}$, and $r$ indices as tools in the identification of severity, frequency, and extent of drought episodes has been used.

Standardized precipitation index The standardized precipitation index (SPI) calculation for any station is based on a series of accumulated precipitation for a fixed time scale of interest (i.e., 1, 3, 6, 9, 12, .. months). Such a series is fitted to a probability distribution, which is then transformed into a normal distribution so that the mean SPI for the location and desired period is zero (Edwards and McKee 1997). Each drought episode has a duration defined by its beginning and end and the intensity for each month during which the episode continues. Therefore, a drought episode occurs any time the SPI is continuously negative and reaches an intensity of -1.0 or less. The positive sum of the SPI for all the months within a drought event can be termed drought. In this research, the self-calibrated SPI (scSPI) was used for the Czech drought conditions. Being inspired by Dubrovsky et al. (2008), we applied a similar original algorithm to calculate SPI for a single reference station or an aggregated SPI for all stations (in our case Zatec and 56 aggregate stations). For more details regarding the methodology, see Dubrovsky et al. (2008). The present version of SPI uses a gamma distribution whose parameters are estimated separately for each of the 6 months of the warm period and/or values for different time scales: $1,2,3$, and 6 months. The Pearson test $\left(\phi_{\mathrm{e}}^{2}\right)$ was used to check the goodness of fit for each data set. The $\phi_{\mathrm{e}}^{2}$ statistical results showed that the data fitted the gamma probability density when the time scales were less than 6 months. Based on our research results, we recommend the agriculturist to use the SPI of 6 months or less. For the SPI, the categories go from extreme drought $(\mathrm{SPI} \leq-2)$ to extreme wet $(\mathrm{SPI} \geq 2)$, with normal conditions being $(-1,+1)$. In our analysis, the SPI defined a drought episode, when the SPI was always below 0 .

The $r$ index This represents a percentage of long-term precipitation. The $r$ is permitting quite an effective estimate of a drought episode when used for a single region or a single season. It is calculated by dividing the actual precipitation by the long-tem precipitation amount and multiplying it by $100 \%$. This index, based solely upon rainfall, has a wide application in many regions around the world. It has been used with great success in regions, where rainfall is normally received at sufficiently frequent intervals, and droughts or dry spells appear in short periods. For the $r$, the categories range from extreme drought $(r \leq$ $20 \%)$ to extreme wet $(r \geq 220 \%)$ with a normal season (or a month) falling within the range of $60 \%$ to $140 \%$.

The $S_{i}$ drought index It was developed by Ped (1975) and makes it possible to determine agricultural drought. The $S_{\mathrm{i}}$ index has been widely used for drought monitoring in the Commonwealth of Independent States, and there are some attempts to use it in Central Europe as well. The $S_{\mathrm{i}}$ has a number of important advantages over the PDSI-index: It is simpler to calculate, it does not have a constant or coefficient, and it can be calculated for any period and site of interest. The disadvantage of $S_{\mathrm{i}}$ index is its dependence on the availability and quality of long data series of soil moisture and an insufficient number of observation stations. This drought index was developed to detect drought and wet periods and distinguish "atmospheric drought" or "pedological drought". It represents a sum of extreme weather conditions. $S_{\mathrm{i}}$ is expressed by the following equation:

$S_{\mathrm{i}}(\tau)=\frac{\Delta T}{\sigma T}-\frac{\Delta R}{\sigma R}-\frac{\Delta E}{\sigma E}$

where $\Delta T=t_{\tau}-t_{n} ; \Delta R=r_{\tau}-r_{n}$, and $\Delta E=e_{\tau}-e_{n}$

$i$ and $\tau \quad$ climatological station and time, respectively

$t_{\tau} \quad$ monthly mean air temperatures in $\tau-\mathrm{a}$ specific year

$t_{n} \quad$ long-term monthly mean air temperatures

$r_{\tau} \quad$ monthly precipitation amounts in $\tau-\mathrm{a}$ specific year

$r_{n} \quad$ long-term monthly precipitation amounts

$e_{\tau} \quad$ monthly amount of moisture in a $0-100$-cm soil layer in $\tau$-a specific year long-term amount of moisture in a $0-100-\mathrm{cm}$ soil layer 
$\sigma T, \sigma R$, and $\sigma E$ root-mean-square deviation in monthly temperature, precipitation, and moisture of soil, respectively.

It should be noted that the soil moisture measurements and calculated values are not always available. Therefore, when calculating the index, it is possible to use the simplified form without soil moisture. Then, the $S_{\mathrm{i}}$ may also be calculated by three methods $\left(S_{\mathrm{i}}-\mathrm{m}-\right.$ meteorological drought, $S_{\mathrm{i}} \mathrm{-p}$ - pedological drought, and $S_{\mathrm{i}}$-a-agricultural drought). Firstly, in case of the identification of meteorological drought or "atmospheric drought" as defined by Ped (1975), only the first and second parameters of the equation can be calculated:

$$
\begin{aligned}
& S_{\mathrm{i}}-m(\tau)=\frac{\Delta T}{\sigma T}-\frac{\Delta R}{\sigma R} \quad \text { or } \\
& S_{\mathrm{i}}-m(\tau)=\left(\frac{t_{\tau}-t_{n}}{\sigma T}\right)-\left(\frac{r_{\tau}-r_{n}}{\sigma R}\right)
\end{aligned}
$$

Secondly, "pedological drought" (drought in the soil) can be formulated as:

$S_{\mathrm{i}}-p(\tau)=\frac{\Delta E}{\sigma E} \quad$ or $\quad S_{\mathrm{i}}-p(\tau)=\left(\frac{{ }^{e} \tau^{-e} n}{\sigma E}\right)$

Thirdly, agricultural drought as a complex event may also be identified by Eq. 6 .

$S_{\mathrm{i}}-a(\tau)=\left(\frac{t_{\tau}-t_{n}}{\sigma T}\right)-\left(\frac{r_{\tau}-r_{n}}{\sigma R}\right)-\left(\frac{e_{\tau}-e_{n}}{\sigma E}\right)$

The $S_{\mathrm{i}}$ index as well as PDSI indicate how the soil moisture compares with long-term climate conditions and are calculated based on parameters such as precipitation, temperature, and soil moisture conditions. This index provides a measure of the long-term intensity of drought conditions derived from the precipitation and temperature anomalies and their combined effects on the soil water availability to plants. The application of normalized values allows the use of this index for comparing purposes in various situations since it describes a specific meteorological situation regarding some mean level. In our analysis, we included in this index a precipitation-temperature series either from a set of weather stations and/or the single teststation at Žatec (which is situated in the rain shadow). Simultaneously, Doksany observatory (see Fig. 1, number 20 in the map) has the longest statistical series of soil moisture from the Czech Republic. It was selected as a reference station to test the degree of information of $S_{\mathrm{i}}$-a index in the identification of agricultural drought (19612007). Furthermore, $S_{\mathrm{i}}$-a determines drought conditions - if the values of parameters are as follows: $\Delta T>0$ or $\Delta T / \sigma T>$ $0 ; \Delta R<0$ or $\Delta R / \sigma R<0 ; \Delta E<0$ or $\Delta E / \sigma E<0$, then $S_{\mathrm{i}}$-a $>0$. Therefore, for the $S_{\mathrm{i}}$-a, the categories interval ranges from extreme drought $\left(S_{\mathrm{i}}\right.$-a $\left.\geq 3\right)$ to extreme wet $\left(S_{\mathrm{i}} \mathrm{a} \leq-3\right)$, with the normal range falling between -1 and +1 . The criteria for meteorological and agricultural droughts proposed in our analysis are included in Table 2.

The criteria of the index $S_{\mathrm{i}}-\mathrm{m}$ are useful for the estimation of monthly droughts. However, droughts can occur, for example, only at the end of 1 month and continue into the following month. In such a case, the first month may not be assessed as dry on the basis of the $S_{\mathrm{i}}$ index, despite the drought having occurred. It has, therefore, been proposed to determine drought by means of the $S_{\mathrm{i}}-\mathrm{m}$ and to use an alternative approach. This approach, if we consider the data of the adjacent months to be independent, requires that we take $S_{\mathrm{i}}-m \geq \frac{2}{\sqrt{N}}$, where $N$ is the number of combined months. This has been put to test in the assessment of droughts in Czechia, both for the entire warm period and for individual seasons. In this case, for the warm period, the computation was carried out with the following data: $S_{\mathrm{i}}-m \geq \frac{1}{\sqrt{6}} ; \quad S_{\mathrm{i}}-m \geq \frac{2}{\sqrt{6}} ; \quad S_{\mathrm{i}}-m \geq \frac{3}{\sqrt{6}}$; $S_{\mathrm{i}}-m \geq \frac{4}{\sqrt{6}}$, that provided the thresholds given in Table 2 . In the evaluation of drought during the spring and autumn seasons, the period of vegetation was taken into account, and hence, the calculation was carried out for only 2 months. The criteria obtained for these seasons were $S_{\mathrm{i}}-m \geq \frac{1}{\sqrt{2}} ; S_{\mathrm{i}}-m \geq \frac{2}{\sqrt{2}} ; S_{\mathrm{i}}-m \geq \frac{3}{\sqrt{2}} ; S_{\mathrm{i}}-m \geq \frac{4}{\sqrt{2}}$. For
Table 2 The new drought criteria proposed for different indices and tested on the territory of the

\begin{tabular}{|c|c|c|c|c|}
\hline \multirow[t]{2}{*}{ Indices } & \multicolumn{4}{|c|}{ Drought severity classification } \\
\hline & Mild & Moderate & Severe & Extreme \\
\hline$S_{\mathrm{i}}-\mathrm{m}$ at time scale 6 months & $0.41 \leq S_{\mathrm{i}}-\mathrm{m}<0.81$ & $0.81 \leq S_{\mathrm{i}}-\mathrm{m}<1.22$ & $1.22 \leq S_{\mathrm{i}}-\mathrm{m}<1.63$ & $S_{\mathrm{i}}-\mathrm{m} \geq 1.63$ \\
\hline$S_{\mathrm{i}}-\mathrm{m}$ at time scale 3 months & $0.58 \leq S_{\mathrm{i}}-\mathrm{m}<1.15$ & $1.15 \leq S_{\mathrm{i}}-\mathrm{m}<1.73$ & $1.73 \leq S_{\mathrm{i}}-\mathrm{m}<2.31$ & $S_{\mathrm{i}}-\mathrm{m} \geq 2.31$ \\
\hline$S_{\mathrm{i}}$-m at time scale 2 months & $0.71 \leq S_{\mathrm{i}}-\mathrm{m}<1.41$ & $1.41 \leq S_{\mathrm{i}}-\mathrm{m}<2.12$ & $2.12 \leq S_{\mathrm{i}}-\mathrm{m}<2.86$ & $S_{\mathrm{i}}-\mathrm{m} \geq 2.86$ \\
\hline$S_{\mathrm{i}}-\mathrm{m}$ at time scale 1 month & $0 \leq S_{\mathrm{i}}-\mathrm{m}<1$ & $1 \leq S_{\mathrm{i}}-\mathrm{m}<2$ & $2 \leq S_{\mathrm{i}}-\mathrm{m}<3$ & $S_{\mathrm{i}}-\mathrm{m} \geq 3$ \\
\hline$S_{\mathrm{i}}$-a at time scale 1 month & $1 \leq S_{\mathrm{i}}-\mathrm{a}<2$ & $2 \leq S_{\mathrm{i}}-\mathrm{a}<3$ & $3 \leq S_{\mathrm{i}}-\mathrm{a}<4$ & $S_{\mathrm{i}-\mathrm{a} \geq 4}$ \\
\hline$S_{\mathrm{i}}$-p at time scale 1 month & $0 \geq S_{\mathrm{i}}-\mathrm{p}>-1$ & $-1 \geq S_{\mathrm{i}}-\mathrm{p}>-2$ & $-2 \geq S_{\mathrm{i}}-\mathrm{p}>-3$ & $S_{\mathrm{i}-\mathrm{p}} \leq-3$ \\
\hline SPI & 0 to -0.99 & -1.00 to -1.49 & -1.50 to -1.99 & $\leq-2.00$ \\
\hline
\end{tabular}
Czech Republic 
the summer, when drought was calculated for 3 months, the following data were obtained: $S_{\mathrm{i}}-m \geq \frac{1}{\sqrt{3}} ; S_{\mathrm{i}}-m \geq \frac{2}{\sqrt{3}}$; $S_{\mathrm{i}}-m \geq \frac{3}{\sqrt{3}}$ and $S_{\mathrm{i}}-m \geq \frac{4}{\sqrt{3}}$. In this paper, the use of this approach allows the identification of drought events in Czechia on the basis of the following time scale: 1 month $\left(S_{\mathrm{i}}-\mathrm{m}-1\right), 2$ months $\left(S_{\mathrm{i}}-\mathrm{m}-2\right), 3$ months $\left(S_{\mathrm{i}}-\mathrm{m}-3\right)$, and 6 months $\left(S_{\mathrm{i}}-\mathrm{m}-6\right)$. These time scales reflect the impact of droughts on the availability of the different water resources.

Area extent of drought The extent of drought expressed in the percentage of the affected area is associated with a specified drought severity (or negative SPI values, positive $S_{\mathrm{i}}$ values, and $r \leq 60 \%$ ), which considered the total number of climatological stations as $100 \%$. It was calculated on the basis of territories affected during individual months of the warm period (April-September) of each drought year. The GIS software such as Surfer (by Golden Software) and ArcGis (by ESRI) has been used with the inverse distance weighting (IDW) and kriging interpolation method. These methods produce visually appealing contours and surface plots from irregularly spaced data. Interpolation schemes estimate the value of the surface at locations where no observed data exist, based on the known data values. The resulting $r$ and SPI values in corresponding drought categories are mapped using inverse distance weighting for the $r$ values and kriging for the $S_{\mathrm{i}}$ index. A S-JTSK Krovak EastNorth coordinate system was applied for AcrGIS and the Surfer. The drought observed on the surface of up to $10 \%$ of the territory of Czechia is classified as a local one. The droughts that cover $11-30 \%$ of the territory indicate widespread droughts. The droughts that cover a territory of $31-50 \%$ are considered very widespread, and over $50 \%$ are classified as most extensive (Potop 2003).

\section{Results}

3.1 Combining the SPI, $S_{\mathrm{i}}$, and $r$ indices as a tool for the identification of drought severity, frequency, and area extent

This section describes the drought episodes in Czechia from 56 weather stations, including monthly rainfalls and temperature measurements obtained during the periods of 47 years each. Three meteorological indices (SPI, $S_{i}$, and r) have been applied to define 1 month as a standard time unit of drought period.

Since the Žatec weather station is situated in the rain shadow of the Krušné hory (Ore Mountains) chain and is therefore in the driest region of the country, it was adopted as a reference station for the evaluations of the drought years. The results based on all three indices provided the data for the interval under consideration, which indicate that droughts were observed in 34 years (a total of 53 months) in warm periods, 20 years in spring (23 months), 19 years in summer ( 22 months), and 8 years ( 8 months) experienced autumn droughts (Table 3$)$. The most frequent drought events occurred in April (12 cases) and May (11). The less frequent drought years occurred in August (five cases). Using only $S_{\mathrm{i}}-\mathrm{m}$ calculations, there were 3 months with extreme drought, 17 months with severe drought, and 44 months that suffered from moderate or mild drought (Fig. 4a-b). The most extreme drought months for the entire reference period were recorded in the following cases: April (2007, 2000), May (2002), June (2003, 2000), July (2006, 1994), August (2003, 1992), September (2006, 1982), October (2001, 1967), November (2006, 1994, and 2003), December (2006, 1971). The longest drought spells were recorded during 4 months in 1964 and 2003. As can be seen in Fig. $4 \mathrm{a}-\mathrm{b}$, the $S_{\mathrm{i}}-\mathrm{m}$ index has registered the highest positive value in August $2003\left(S_{\mathrm{i}}-\mathrm{m}=5.0\right)$ and April $2007\left(S_{\mathrm{i}}-\mathrm{m}=4.3\right)$. By contrast, the highest negative value of the $S_{\mathrm{i}}-\mathrm{m}$ index was reached in March $2000\left(S_{\mathrm{i}}-\mathrm{m}=-5.3\right)$. During this month, there was a heavy precipitation event; hence, the same high values of both indices $r \geq 120 \%$ and $S_{\mathrm{i}}-\mathrm{mi} \geq 2$ were registered for the majority the weather stations. Thus, $S_{\mathrm{i}}-\mathrm{m}$ index has a high capacity to identify both drought and wet months on the territory of Czechia. Table 3 shows that of the three drought indices, the SPI is the less informative for describing droughts, especially in the months of May and August (only three to six cases). At the same time, in July, the SPI had almost the same share as $r$ and $S_{\mathrm{i}}$-m indices (nine, ten, and 11 cases, respectively).

Table 3 describes only the data that relate to the Žatec weather. Data for all other parts of the country have been processed in the same way. For each of the 56 weather stations, the numerical values of the drought indices have been calculated, which then allowed us to evaluate the years according to drought intensity and affected area. We found that moderate and severe intensity droughts are most frequent in April and July, while in June (35 cases), droughts are mostly middle and moderate. From the total number of drought months (168) in the warm period, $65 \%$ of the months are June, July, and April. Having analyzed the characteristic features of the drought in the whole territory of the country, we can state that approximately every fifth year suffers from severe drought during the spring and/or summer.

For the existing soil moisture data, Eqs. 4, 5, and 6 were applied to calculate their statistical parameters and to identify the contribution of $S_{\mathrm{i}}-\mathrm{m}$ and $S_{\mathrm{i}}$-p on the $S_{\mathrm{i}}$-a. Thus, the data analysis in Table 4 makes it possible to reach the following results:

- The high positive values of intensity $S_{\mathrm{i}}$-a $\geq 2.0$ agricultural drought index are due to the positive 
Table 3 Monitoring the evolution of the drought/wet conditions for the reference station (Žatec)

\begin{tabular}{|c|c|c|c|c|c|c|c|c|c|c|c|c|c|c|c|c|c|c|}
\hline \multirow[t]{2}{*}{ Years } & \multicolumn{3}{|c|}{ April } & \multicolumn{3}{|l|}{ May } & \multicolumn{3}{|c|}{ June } & \multicolumn{3}{|l|}{ July } & \multicolumn{3}{|c|}{ August } & \multicolumn{3}{|c|}{ September } \\
\hline & $r$ & SPI & $S_{\mathrm{i}}-\mathrm{m}$ & $r$ & SPI & $S_{\mathrm{i}}-\mathrm{m}$ & $r$ & SPI & $S_{\mathrm{i}}-\mathrm{m}$ & $r$ & SPI & $S_{\mathrm{i}}-\mathrm{m}$ & $r$ & SPI & $S_{\mathrm{i}}-\mathrm{m}$ & $r$ & SPI & $S_{\mathrm{i}}-\mathrm{m}$ \\
\hline 1961 & & $m / e$ & $S$ & & & $\mathrm{~W}$ & & & & & & $\mathrm{~W}$ & & & & $m / e$ & $m / e$ & $m / e$ \\
\hline 1962 & & & $m / e$ & & & $\mathrm{w}$ & & & $\mathrm{W}$ & & & $\mathrm{W}$ & $m / e$ & & & & & \\
\hline 1963 & & & & & & & $\mathrm{w}$ & $\mathrm{W}$ & $\mathrm{W}$ & & & $\mathrm{W}$ & & & & & & \\
\hline 1964 & & & & $S$ & & $m / e$ & $S$ & $S$ & $S$ & $E$ & $S$ & $S$ & $S$ & & & $S$ & $m / e$ & $m / e$ \\
\hline 1965 & $\mathrm{~W}$ & & $\mathrm{~W}$ & W & $\mathrm{W}$ & $\mathrm{w}$ & & & & $\mathrm{W}$ & & $\mathrm{W}$ & $m / e$ & $m / e$ & & $\mathrm{w}$ & $\mathrm{W}$ & $\mathrm{w}$ \\
\hline 1966 & & & & $S$ & $m / e$ & & & & & & & $\mathrm{~W}$ & & & & & & \\
\hline 1967 & $m / e$ & & & $\mathrm{~W}$ & $\mathrm{~W}$ & $\mathrm{w}$ & $\mathrm{w}$ & $\mathrm{W}$ & $\mathrm{w}$ & & & & & & & $\mathrm{w}$ & $\mathrm{W}$ & $\mathrm{w}$ \\
\hline 1968 & $\mathrm{~W}$ & & & $S$ & & & $\mathrm{w}$ & & & $m / e$ & $m / e$ & & & & & & & \\
\hline 1969 & $\mathrm{~W}$ & & $\mathrm{~W}$ & & & $m / e$ & $\mathrm{w}$ & & $\mathrm{W}$ & $S$ & $m / e$ & $m / e$ & & & & & & \\
\hline 1970 & & & $\mathrm{~W}$ & & & $\mathrm{w}$ & & & & $m / e$ & $m / e$ & & w & $\mathrm{W}$ & W & $m / e$ & & \\
\hline 1971 & $m / e$ & & $m / e$ & w & $\mathrm{W}$ & $\mathrm{w}$ & & & $\mathrm{W}$ & $S$ & $S$ & $m / e$ & & & & & & \\
\hline 1972 & & & & & & & & & & & & & $m / e$ & & & & & \\
\hline 1973 & & & W & $m / e$ & & & & & & & & & $E$ & $m / e$ & $m / e$ & $S$ & $m / e$ & $S$ \\
\hline 1974 & $S$ & $m / e$ & $m / e$ & & & w & & & w & $m / e$ & $m / e$ & & & & & w & W & W \\
\hline 1975 & $S$ & $m / e$ & & & & & & & & & & & & & $m / e$ & & & \\
\hline 1976 & & & & & & & $m / e$ & & $m / e$ & & & $m / e$ & & & & & & \\
\hline 1977 & & & W & & & & w & W & w & & & & W & w & w & & & \\
\hline 1978 & & & & W & $\mathrm{W}$ & w & & & w & & & & & & & & & \\
\hline 1979 & $\mathrm{w}$ & $\mathrm{w}$ & W & $S$ & $m / e$ & $m / e$ & & & $m / e$ & & & W & $m / e$ & & & w & W & w \\
\hline 1980 & & & $\mathrm{~W}$ & & & & & & & w & W & $\mathrm{W}$ & $m / e$ & & & w & & \\
\hline 1981 & & & & & & & $S$ & $S$ & $S$ & w & w & $\mathrm{W}$ & & & & & & \\
\hline 1982 & $S$ & $m / e$ & & & & & & & & & & & & & & $S$ & $m / e$ & $S$ \\
\hline 1983 & $\mathrm{w}$ & $\mathrm{w}$ & W & & & & $S$ & & $m / e$ & $S$ & $m / e$ & $E$ & W & w & w & & & \\
\hline 1984 & $\mathrm{~W}$ & W & W & & & w & & & & W & & W & & & & & & \\
\hline 1985 & $m / e$ & & $m / e$ & $S$ & $m / e$ & $S$ & & & $\mathrm{~W}$ & $\mathrm{~W}$ & & & W & w & & $S$ & $m / e$ & $m / e$ \\
\hline 1986 & & & & W & $\mathrm{w}$ & $\mathrm{w}$ & $m / e$ & $m / e$ & $m / e$ & $m / e$ & & & W & w & W & & & \\
\hline 1987 & $\mathrm{~W}$ & & & & & w & & & W & & & & & & & w & w & \\
\hline 1988 & $S$ & $m / e$ & $m / e$ & $S$ & $m / e$ & $S$ & & & & w & & & & & & $\mathrm{w}$ & W & \\
\hline 1989 & $\mathrm{w}$ & w & $\mathrm{W}$ & $m / e$ & & $m / e$ & & & & & & & & & & & & \\
\hline 1990 & & & & $S$ & & $m / e$ & w & & & $E$ & $S$ & $m / e$ & & & $m / e$ & & & \\
\hline 1991 & & & & & & $\mathrm{~d}$ & w & W & W & $m / e$ & $m / e$ & $S$ & & & & & & $m / e$ \\
\hline 1992 & $\mathrm{~W}$ & & & $S$ & $m / e$ & $S$ & w & & & w & w & & $S$ & & $S$ & & & \\
\hline 1993 & $E$ & $S$ & $E$ & W & & $m / e$ & W & & $\mathrm{w}$ & & & W & & & & & & \\
\hline 1994 & $\mathrm{~W}$ & w & W & W & $\mathrm{W}$ & & $m / e$ & $S$ & $S$ & & & $S$ & w & & & & & \\
\hline 1995 & & & & W & & w & w & w & W & & & $m / e$ & & & & & & \\
\hline 1996 & & & & & & & w & W & $\mathrm{w}$ & & & W & w & & W & & & \\
\hline 1997 & & & w & $m / e$ & & $m / e$ & & & & w & w & $\mathrm{W}$ & $m / e$ & & $m / e$ & $m / e$ & & $m / e$ \\
\hline 1998 & $m / e$ & & $S$ & $E$ & $m / e$ & $S$ & & & & & & & & & & w & W & w \\
\hline 1999 & & & & $m / e$ & & $m / e$ & & & & & & $m / e$ & & & & & & $m / e$ \\
\hline 2000 & $m / e$ & & $E$ & & & $m / e$ & $m / e$ & & $S$ & & & & & & $m / e$ & & & \\
\hline 2001 & & & & & & $m / e$ & $m / e$ & $S$ & & & & & & & $m / e$ & w & & w \\
\hline 2002 & & & & & & $m / e$ & & & $m / e$ & w & & & w & w & w & $\mathrm{w}$ & W & w \\
\hline 2003 & & & & & & $m / e$ & $m / e$ & $m / e$ & $S$ & w & & & $E$ & $m / e$ & $S$ & $S$ & $S$ & $m / e$ \\
\hline 2004 & $S$ & $m / e$ & $m / e$ & W & & $\mathrm{w}$ & & & & & & & & & & & & \\
\hline 2005 & & & & w & $\mathrm{w}$ & w & $m / e$ & $m / e$ & & & & & & & & & & \\
\hline 2006 & w & w & W & & & & & & & & & $m / e$ & & & & $m / e$ & $m / e$ & $m / e$ \\
\hline 2007 & $E$ & $S$ & $E$ & & & & & & $m / e$ & & & & & & & & & \\
\hline
\end{tabular}


Table 3 (continued)

\begin{tabular}{|c|c|c|c|c|c|c|c|c|c|c|c|c|c|c|c|c|c|c|}
\hline \multirow[t]{2}{*}{ Years } & \multicolumn{3}{|c|}{ April } & \multicolumn{3}{|c|}{ May } & \multicolumn{3}{|c|}{ June } & \multicolumn{3}{|c|}{ July } & \multicolumn{3}{|c|}{ August } & \multicolumn{3}{|c|}{ September } \\
\hline & $r$ & SPI & $S_{\mathrm{i}}-\mathrm{m}$ & $r$ & SPI & $S_{\mathrm{i}}-\mathrm{m}$ & $r$ & SPI & $S_{\mathrm{i}}-\mathrm{m}$ & $r$ & SPI & $S_{\mathrm{i}}-\mathrm{m}$ & $r$ & SPI & $S_{\mathrm{i}}-\mathrm{m}$ & $r$ & SPI & $S_{\mathrm{i}}-\mathrm{m}$ \\
\hline Cases & 12 & 8 & 11 & 13 & 6 & 16 & 10 & 7 & 11 & 10 & 9 & 11 & 10 & 3 & 7 & 9 & 7 & 10 \\
\hline
\end{tabular}

The table includes the assessment of drought (data in italics), normal (blank table cell), and wet (w) month for each index. The marks indicate the type of drought: $M$ mild, $m / e$ moderate, $S$ severe, and $E$ extreme

values of $S_{\mathrm{i}}-\mathrm{m} \geq 1.5$ meteorological index and the negative values of $S_{\mathrm{i}}-\mathrm{p}<-1.0$ pedological drought index.

- The years when the values of $S_{\mathrm{i}}$-a index had increased due to high values of $S_{\mathrm{i}}$-m index have been observed. For example, the severe July drought years are related

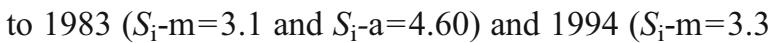
and $\left.S_{\mathrm{i}}-\mathrm{a}=4.6\right)$. In the months of June $\left(S_{\mathrm{i}}-\mathrm{m}=3.6\right.$ and $S_{\mathrm{i}^{-}}$

a

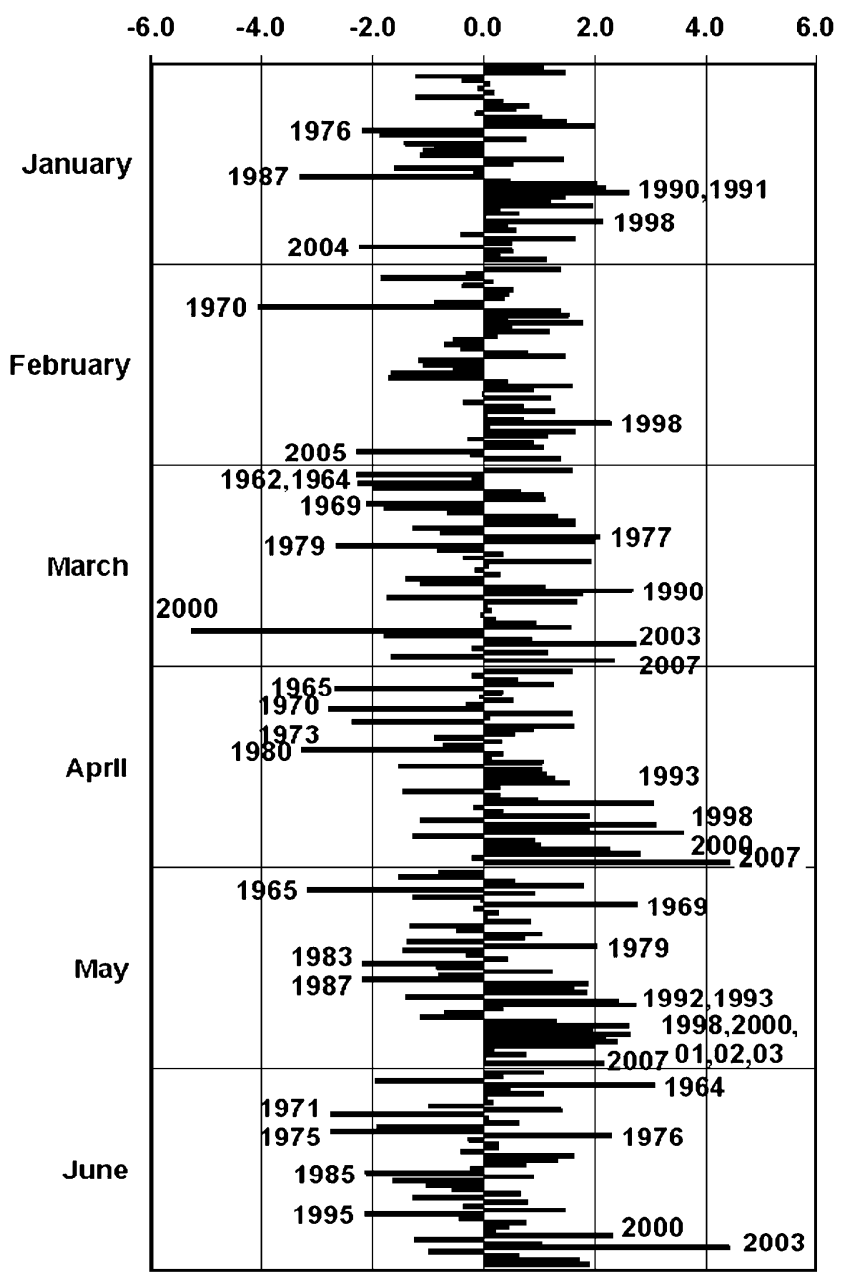

Fig. 4 a-b Evolution of the severity $S_{\mathrm{i}}$-m values representative of the Zatec weather station for the 47 -year time series. Positive values of $S_{\mathrm{i}-}$ $\mathrm{m}$ correspond to drought months; negative values to the humid ones. $\mathrm{a}=6.0)$ and August $\left(S_{\mathrm{i}}-\mathrm{m}=3.3\right.$ and $\left.S_{\mathrm{i}}-\mathrm{a}=5.0\right)$ of 2003 , the highest value of the $S_{\mathrm{i}}$-a index was recorded.

- In June, the greatest contribution to increased intensity agricultural drought $S_{\mathrm{i}}$-a is soil moisture parameter $\left(S_{\mathrm{i}}\right.$-p). As an example, we can use the year 2007, when $S_{\mathrm{i}}$ - index had a larger share than $S_{\mathrm{i}}-\mathrm{m}\left(S_{\mathrm{i}}\right.$ $\mathrm{m}=1.8, S_{\mathrm{i}-\mathrm{p}}=-2.0$ and $S_{\mathrm{i}}$-a=3.8). By contrast, in 1981 , the $S_{\mathrm{i}}$ - $\mathrm{p}$ index had a positive value (it indicates normal

b

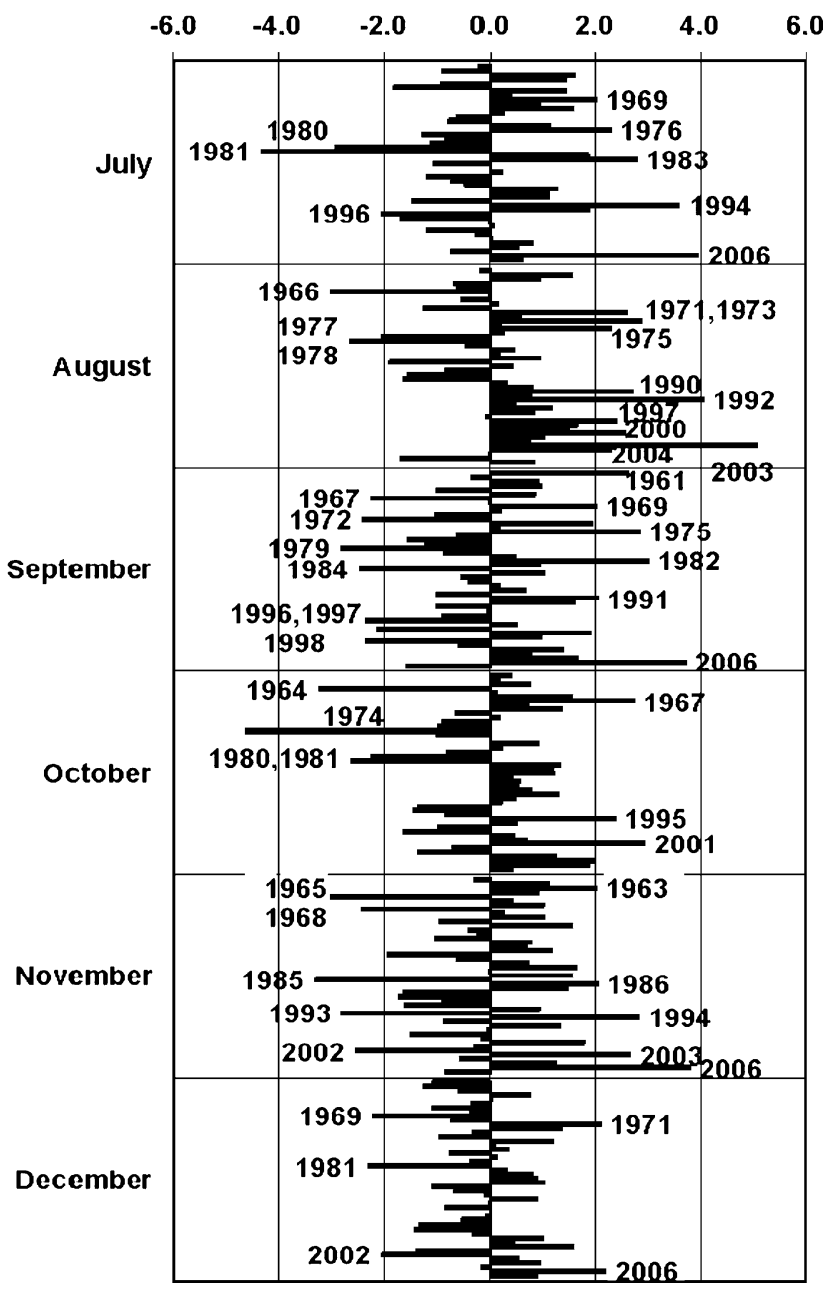

Another interpretation may be made as follows: positive values of $S_{\mathrm{i}}$ $\mathrm{m}$ correspond to a warmer thermal regime during a given period, whereas the negative ones reflect a colder thermal regime 
Table 4 Example of specifying meteorological drought $\left(S_{\mathrm{i}}-\mathrm{m} \geq 0\right)$, pedological drought $\left(S_{\mathrm{i}}-\mathrm{p} \leq 0\right)$, and agricultural drought $\left(S_{\mathrm{i}-\mathrm{a}} \geq 1\right)$ for Doksany Observatory (1961-2007)

\begin{tabular}{|c|c|c|c|c|c|c|c|c|c|c|c|}
\hline \multicolumn{4}{|l|}{ June } & \multicolumn{4}{|l|}{ July } & \multicolumn{4}{|c|}{ August } \\
\hline Year & $S_{\mathrm{i}}-\mathrm{m}$ & $S_{\mathrm{i}-\mathrm{p}}$ & $S_{\mathrm{i}-\mathrm{a}}$ & Year & $S_{\mathrm{i}}-\mathrm{m}$ & $S_{\mathrm{i}-\mathrm{p}}$ & $S_{\mathrm{i}-\mathrm{a}}$ & Year & $S_{\mathrm{i}}-\mathrm{m}$ & $S_{\mathrm{i}} \mathrm{-p}$ & $S_{\mathrm{i}-\mathrm{a}}$ \\
\hline 1964 & 2.8 & -0.8 & 3.6 & 1964 & 2.1 & -1.6 & 3.7 & 1975 & 1.4 & -0.3 & 1.7 \\
\hline 1976 & 1.7 & -0.9 & 2.6 & 1971 & 1.5 & 0.1 & 1.4 & 1992 & 2.7 & -1.5 & 4.3 \\
\hline 1981 & 1.3 & 0.2 & 1.2 & 1976 & 1.9 & -2.2 & 4.2 & 1997 & 2.2 & 0.2 & 2.0 \\
\hline 1992 & 1.5 & -0.6 & 2.1 & 1983 & 3.1 & -1.5 & 4.6 & 2000 & 2.2 & -1.1 & 3.2 \\
\hline 2000 & 2.5 & -1.6 & 4.1 & 1990 & 1.3 & 0.1 & 1.2 & 2003 & 3.3 & -1.7 & 5.0 \\
\hline 2003 & 3.6 & -2.3 & 6.0 & 1992 & 1.2 & 0.0 & 1.2 & & & & \\
\hline 2005 & 1.4 & -2.5 & 4.0 & 1994 & 3.3 & -1.3 & 4.6 & & & & \\
\hline 2006 & 1.5 & -2.1 & 3.6 & 1995 & 2.0 & 0.4 & 1.6 & & & & \\
\hline \multirow[t]{2}{*}{2007} & 1.8 & -2.0 & 3.8 & 1999 & 1.6 & -0.4 & 1.9 & & & & \\
\hline & & & & 2004 & 1.1 & -2.1 & 3.2 & & & & \\
\hline
\end{tabular}

conditions of soil moisture), which contributed to the decreasing intensity of drought $\left(S_{\mathrm{i}}-\mathrm{m}=1.3, S_{\mathrm{i}}-\mathrm{p}=0.2\right.$, and $\left.S_{\mathrm{i}}-\mathrm{a}=1.2\right)$.

Droughts also differ in terms of their spatial characteristics. The areas affected by severe drought evolve gradually, and the regions of maximum drought intensity shift from one season to the next. The local droughts are a characteristic of the north-west and southern areas, while the widespread ones have been observed in the southern and south-eastern parts of the country. The very widespread droughts cover a large territory of up to $50 \%$ of the area and are frequent in the southern, south-eastern, and northwestern parts of Czechia. In the above-mentioned territory, the droughts of severe intensity occurred in dry regions of the country, i.e., South Moravia and the rain shadow of the Krušné hory mountain chain. However, in the rest of the area, droughts of a moderate and mild degree of intensity have been noticed. The most extensive droughts cover the whole territory except the mountain sites. For example, the most extensive drought was registered in 2007 (Fig. 5a-b).

It is not the purpose of this paper to introduce the procedures of the Poisson model for the assessment of the time distribution of the drought episode. For more details regarding the methodology, see Potop and Soukup (2008). We employed the same model tested by Pearson's criteria $\left(\chi_{\mathrm{e}}^{2}\right)$ for Czechia. According to Pearson's test $\left(\chi_{\mathrm{e}}^{2}\right)$, the phenomenon obeys the same rules when the empirical data $\left(\chi_{\mathrm{e}}^{2}\right)$ are smaller than the theoretical $\left(\chi_{\mathrm{t}}^{2}\right)$ ones. Since the smallest $p$ value among the tests performed is less than 0.05 , we can reject the idea that local droughts occurring in June, July, and August come from a Poisson distribution with 95\% confidence. For the other months such as April, May, and September, there were insufficient data to conduct the $\chi^{2}$ test. The $\chi^{2}$ test was not run because the number of observations was too small. As the results in Table 5 show, a

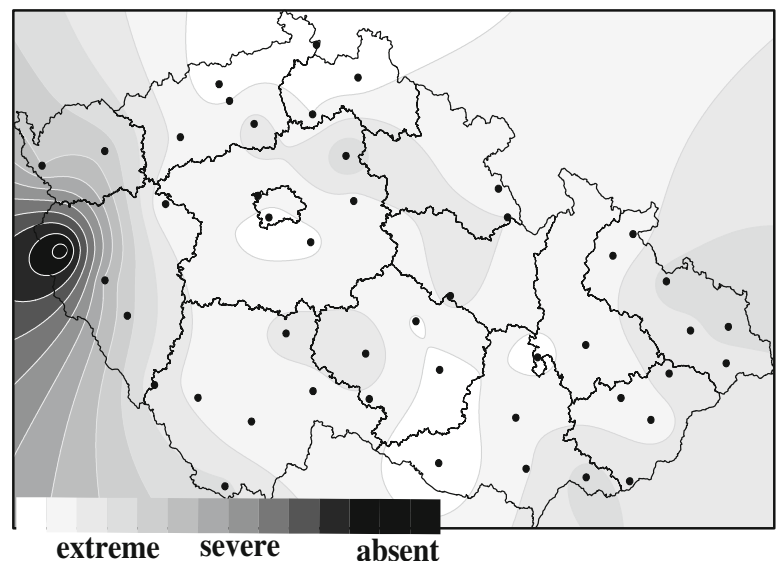

b

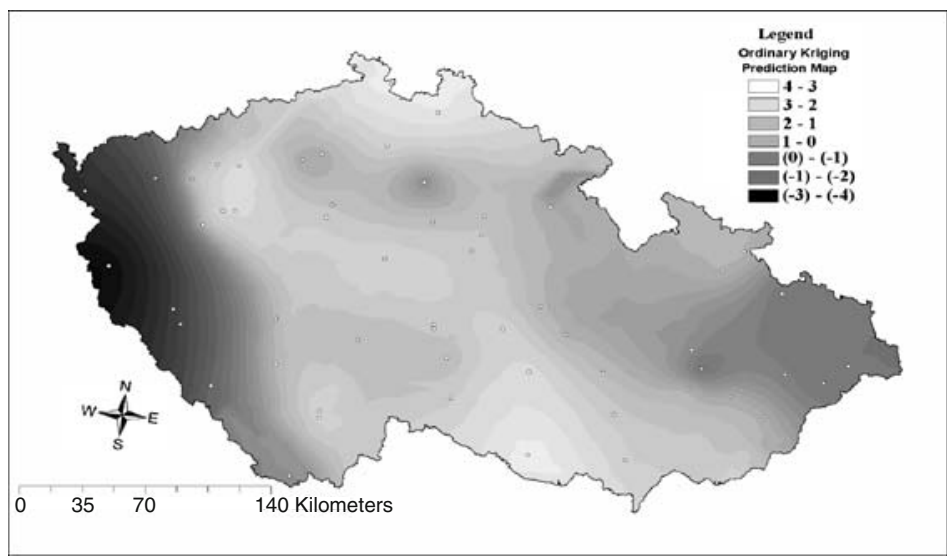

Fig. 5 a-b Delimitation of region affected by drought according to $r(\mathbf{a})$ and $S_{\mathrm{i}}-\mathrm{m}$ (b) indices in April 2007 ( $r$ by the IDW method and $S_{\mathrm{i}}$-m by the kriging interpolation methods) 
Table 5 The Poisson model and values of the time intervals between droughts

\begin{tabular}{|c|c|c|c|c|c|}
\hline \multirow[t]{2}{*}{ Months } & \multirow{2}{*}{$\begin{array}{l}\text { The number of drought } \\
\text { events in time interval } \\
\text { of } 47 \text { years, } n\end{array}$} & \multirow{2}{*}{$\begin{array}{l}\text { The average of time } \\
\text { interval between } \\
\text { drought events, } x\end{array}$} & \multirow[t]{2}{*}{$\begin{array}{l}\text { The predicted drought } \\
\text { frequency, } \lambda, 1 / \operatorname{avg}(x)\end{array}$} & \multicolumn{2}{|c|}{$\begin{array}{l}\text { Pearson criterion } \\
\chi_{\mathrm{e}}^{2}<\chi_{\mathrm{t}}^{2}\end{array}$} \\
\hline & & & & $\chi_{\mathrm{e}}^{2}$ & $\chi_{\mathrm{t}}^{2}(\alpha=0.05)$ \\
\hline \multicolumn{6}{|c|}{ Local (up to $10 \%$ of the territories affected by drought) } \\
\hline April & 3 & 15.7 & 0.06 & - & - \\
\hline May & 4 & 11.8 & 0.08 & - & - \\
\hline June & 10 & 4.7 & 0.21 & 5.99 & 18.30 \\
\hline July & 7 & 6.7 & 0.15 & 0.01 & 14.06 \\
\hline August & 5 & 9.4 & 0.11 & 3.87 & 11.07 \\
\hline September & 4 & 11.8 & 0.08 & - & - \\
\hline \multicolumn{6}{|c|}{ Widespread drought (11-30\%) } \\
\hline April & 15 & 3.1 & 0.32 & 9.44 & 24.99 \\
\hline May & 15 & 3.1 & 0.32 & 9.44 & 24.99 \\
\hline June & 14 & 3.4 & 0.29 & 8.03 & 23.69 \\
\hline July & 14 & 3.4 & 0.29 & 8.03 & 23.69 \\
\hline August & 12 & 3.9 & 0.26 & 5.47 & 21.03 \\
\hline September & 3 & 15.7 & 0.06 & - & - \\
\hline \multicolumn{6}{|c|}{ Very widespread drought $(31-50 \%)$} \\
\hline April & 7 & 6.7 & 0.16 & 0.01 & 14.06 \\
\hline May & 2 & 23.5 & 0.04 & - & - \\
\hline June & 4 & 11.8 & 0.08 & - & - \\
\hline July & 3 & 15.7 & 0.06 & - & - \\
\hline August & 7 & 6.7 & 0.15 & 0.01 & 14.06 \\
\hline September & 8 & 5.9 & 0.17 & 0.55 & 15.51 \\
\hline \multicolumn{6}{|c|}{ Most extensive drought $(<50 \%)$} \\
\hline April & 7 & 6.7 & 0.15 & 0.01 & 14.06 \\
\hline May & 6 & 7.8 & 0.13 & 0.54 & 12.59 \\
\hline June & 6 & 7.8 & 0.13 & 0.54 & 12.59 \\
\hline July & 7 & 6.7 & 0.15 & 0.01 & 14.06 \\
\hline August & 6 & 7.8 & 0.13 & 0.54 & 12.59 \\
\hline September & 5 & 9.4 & 0.11 & 3.87 & 11.07 \\
\hline
\end{tabular}

This model is tested by the $\chi^{2}$ criteria for individual months from the warm period in the Czech Republic. $(-)$ is $\chi_{\mathrm{e}}^{2}>\chi_{\mathrm{t}}^{2}$

the average time intervals between the local droughts for June-July are 4.7 and 6.7 years, respectively. By contrast, in April, May, and September, the number of local droughts diminished from three to four cases with an average time interval ranging from 11.8 to 15.7 years.

Examination of the distributions of the widespread drought has shown that in all the spring and summer months, the number of drought years increases with a greater probability, but the length of intervals between them decreases. Thus, every third year, a widespread drought was recorded. Throughout the whole period of this study, there were about eight and five very widespread and most extensive droughts in the month of September, which can be expected once in 6 and 9 years, respectively. According to the obtained results, the droughts from April and July, with a guarantee of $95 \%$, occur throughout most of the entire country. Conforming to Poisson's model, an increased frequency of the widespread and very widespread droughts has been noticed, together with a diminishing interval between them. The extreme drought episodes usually affected wide areas of Czechia, but sometimes a drought episode affects one region, while the other areas are subject to humid conditions.

3.2 The relationship between $S_{\mathrm{i}}$-m drought index and Cm index of variability of cereal crops

In this section, the drought risk to crops was analyzed by identifying the relationships between the fluctuation of crop yields $(\mathrm{Cm})$ and drought (Si-m) based on the multiple regression analysis with stepwise selection. The stepwise regression model has selected only the drought months, 
which have a significant impact on individual cereal crops. Table 6 shows the results of fitting a multiple linear regression model to $S_{\mathrm{i}}-\mathrm{m}$ index for 6 months (AprilSeptember). Since the $p$ value in Table 6 is less than 0.05 , there is a statistically significant relationship between the variables at the $90 \%$ confidence level. The coefficient of determination $\left(R^{2}\right)$ describes the proportion of the total variance in the observed data that can be explained by the model. It ranges from 0 to 1 , where the higher values indicate better agreement between the observed and predicted data. The interpretation of the coefficient of determination $\left(R^{2}\right)$ is relatively straightforward $\left(R^{2}\right.$ value of 0.45 indicates that the model explains $45 \%$ of the variability in the observed data).

As can be seen from the coefficient of determination $\left(R^{2}\right)$, drought impact has a significant influence on crop yields in CR: the impact of $S_{\mathrm{i}}$-m index on Cm amounts to $55-89 \%$ for winter crops and over $45 \%$ for spring cereals (Table 6). The validity of the approach is confirmed in several ways. First, it is a highly statistically significant regression model ( $p$ value is less 0.05 ). Second, the growth stages of cereal crops clearly show the negative signs of $S_{\mathrm{i}}{ }^{-}$ $m$ index in a given set of months when drought conditions are significant for yield forming. Wheat crops have the highest demands for sufficient moisture from the end of April to mid-June, when it consumes $70 \%$ its total water need. Barley crops, due to their germ roots, do not have a great demand for the moisture, and they are able to obtain water in times of drought in deeper layers. Moisture conditions, however, significantly affect the quality of spring malting barley, where excess moisture extends the vegetation period. Most susceptible to drought is the spring barley in May and early June. Oats is difficult to produce when there is insufficient moisture, and the droughts are most damaging in its early stages (May-June). Maize can acquire water very well from deeper layers with its root system and is resistant to dry periods. It has increased demands for moisture during the flowering period (JulyAugust). For example, a severe drought in 1992 affected all cereals with the exception of maize (Fig. 6a-b). That year's drought was widespread in Germany (crop production was reduced by $22 \%$ ), Hungary, Bulgaria, Moldova, and much of western Russia.

Thus, higher yields of winter rye, maize, and barley were found in the years with $S_{\mathrm{i}}-\mathrm{m}$ index drought with values of -1 and -2 (mean humidity) during the growing period. In the years with the spring drought (April to May), lower yields of spring wheat and spring barley were registered $\left(R^{2}=0.76\right.$ $0.79)$. Drought spells in May caused lower yields $(-1.5 \sigma)$ of oats $\left(R^{2}=0.72\right)$. If drought occurred during June and August, then $70 \%$ of the lower yield years (with $-\sigma$ to $-1.5 \sigma$ ) were registered for maize $\left(R^{2}=0.45\right)$. In agreement with the $S_{\mathrm{i}}-\mathrm{m}$ index, winter wheat and winter barley were affected by a severe drought in May-June. According to the obtained results, the low-yielding years occurred in 13 cases for these crops: winter wheat, spring wheat, winter barley, and oats. A low-yielding year influenced by drought is likely to occur once in about 3.5 years, as shown by spring barley and maize -12 cases (once in 3.8 years) and winter rye recorded 14 cases (3.2 years). Taking into consideration the nonhomogeneity of demand by cereal crops on the hydrothermic conditions during the vegetation period, different responses by the crops in the low-yielding years had been observed. For example, in the year 1976, summer drought occurred, and as a result, the yield was reduced in the crops with $-0.5 \sigma$ for spring barley, winter barley, and maize; $-1.5 \sigma$ for winter wheat, spring wheat, and oats. By contrast, winter rye in this year was least affected by the summer drought. The summer 1976 is characterized in the literature as being exceptional for Europe, with severe droughts reaching from Scandinavia to France, affecting in particular Sweden, Denmark, the Netherlands, Northern France, England, Scotland, and Ireland later also spreading to Eastern Europe, while "the impact was worst in South-East England with supply restrictions" (Bradford 2000).

Among the winter cereals, winter rye shows the highest $\mathrm{Cm}$ fluctuations due to spring drought. The insufficient water supply and low temperatures in winter time and early
Table 6 The relationship between $S_{\mathrm{i}}$-m drought index and $\mathrm{Cm}$ of cereal crops ( $\mathrm{t} / \mathrm{ha}$ ) is estimated by regression equation: $\mathrm{Cm}=a_{0}+a_{1 *} S_{\mathrm{i}}-\mathrm{m} \tau$, where the dependent variable is $\mathrm{Cm}$ (variability of cereal crops) and the independent variable is $S_{\mathrm{i}}$-m drought index; impact of drought $\left(S_{\mathrm{i}}-\mathrm{m}\right)$ on the $\mathrm{Cm}$ is estimated by the signs values of a regression coefficient $\left(a_{1}, ; \tau\right.$ is the selection of the corresponding months and $a_{0}$ is the constant

\begin{tabular}{llll}
\hline & $R^{2}$ & $p$ & Regression equation, Cm=a $a_{0}+a_{i} S_{\mathrm{i}}-\mathrm{m} \tau$ \\
\hline Winter wheat & 0.55 & 0.05 & $\mathrm{Cm}=8.01-1.42 S_{\mathrm{i}}-\mathrm{m}_{\text {May }}-0.63 S_{\mathrm{i}}-\mathrm{m}_{\text {June }}$ \\
Spring wheat & 0.79 & 0.01 & $\mathrm{Cm}=7.32-1.06 S_{\mathrm{i}}-\mathrm{m}_{\text {April }}-2.19 S_{\mathrm{i}}-\mathrm{m}_{\text {May }}$ \\
Winter barley & 0.65 & 0.00 & $\mathrm{Cm}=10.03-1.63 S_{\mathrm{i}}-\mathrm{m}_{\text {April }}-2.41 S_{\mathrm{i}}-\mathrm{m}_{\text {May }}$ \\
Spring barley & 0.76 & 0.03 & $\mathrm{Cm}=8.21-1.25 S_{\mathrm{i}}-\mathrm{m}_{\text {April }}-2.03 S_{\mathrm{i}}-\mathrm{m}_{\text {May }}$ \\
Winter rye & 0.89 & 0.01 & $\mathrm{Cm}=7.42-1.52 S_{\mathrm{i}}-\mathrm{m}_{\text {April }}-0.41 S_{\mathrm{i}}-\mathrm{m}_{\text {May }}-0.19 S_{\mathrm{i}}-\mathrm{m}_{\text {June }}$ \\
Oats & 0.72 & 0.04 & $\mathrm{Cm}=8.32-2.75 S_{\mathrm{i}}-\mathrm{m}_{\text {May }}$ \\
Maize & 0.45 & 0.05 & $\mathrm{Cm}=10.14+0.20 S_{\mathrm{i}}-\mathrm{m}_{\text {April }}-1.21 S_{\mathrm{i}}-\mathrm{m}_{\text {June }}-0.36 S_{\mathrm{i}}-\mathrm{m}_{\text {August }}$
\end{tabular}




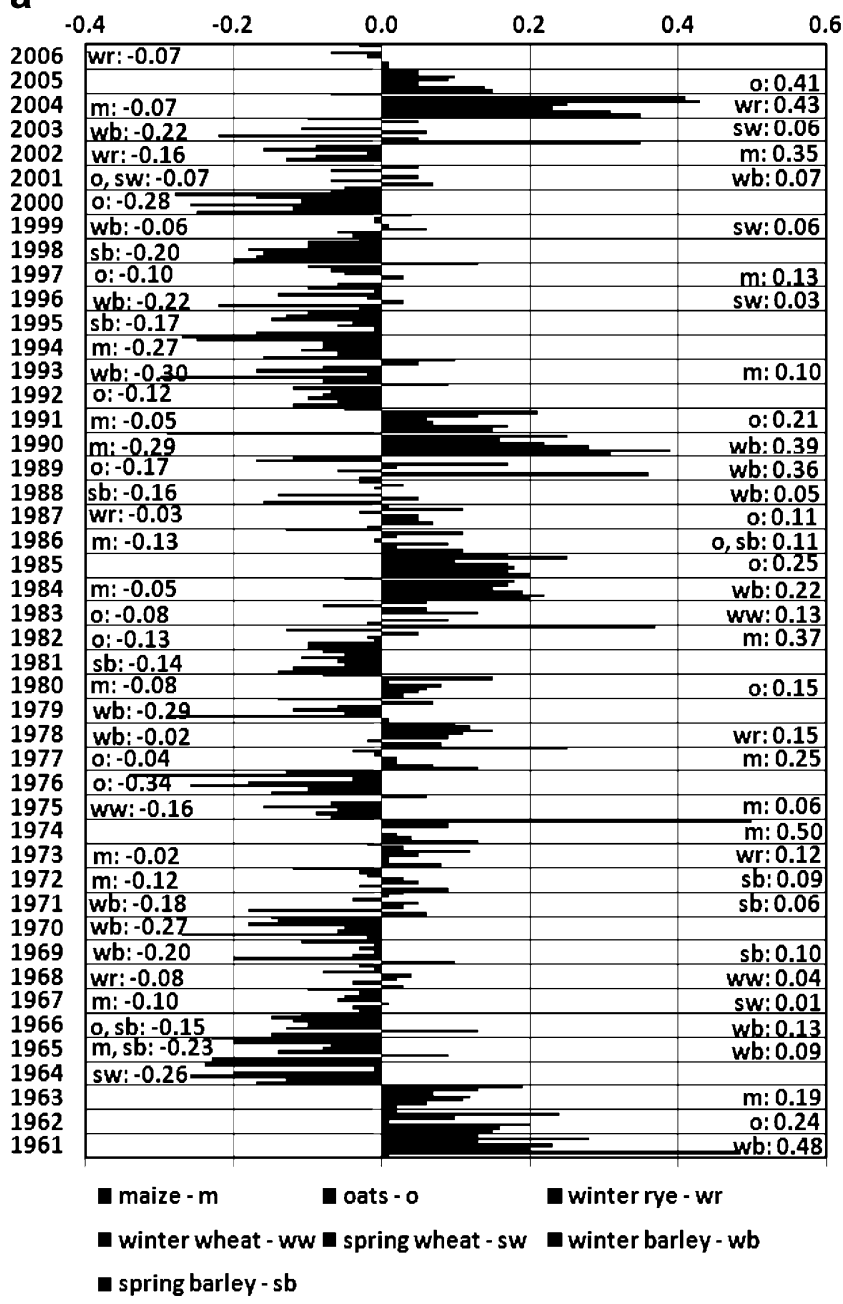

b

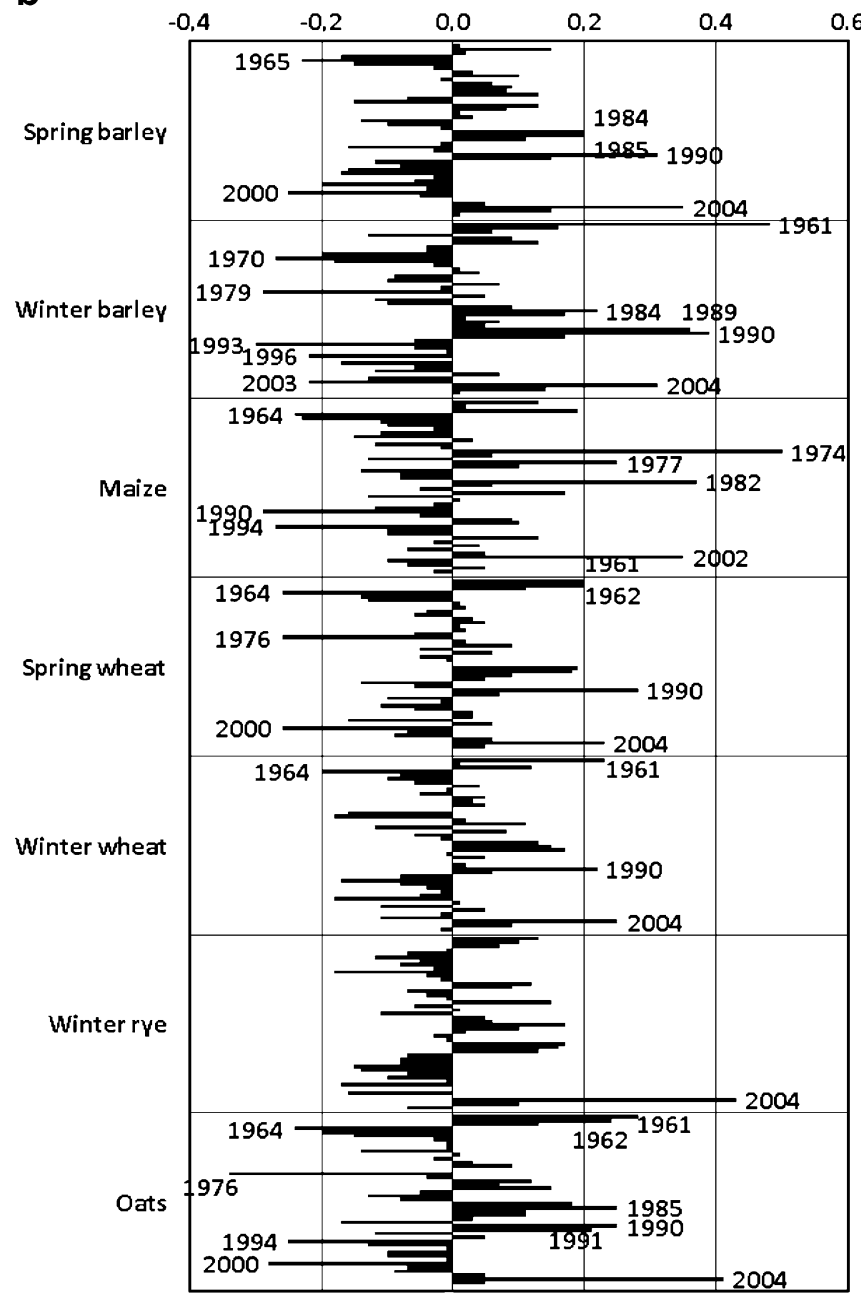

Fig. 6 a-b Departures of the annual yield $y_{i}^{(T)}$ of individual cereal crops: $y_{i}^{(T)}$ positive values denote increases in crops yields due to favorable meteorological conditions, and negative values indicate a reduction in the crop yield due to drought conditions

spring drought are unfavorable for the growth and yield development of winter cereals in general. Of the spring cereals, maize yield is the least sensitive to the drought. During the last decade, a high variation in the yield of all cereals was observed, especially from 2000 to the present time (Fig. 3). In this period, the cereal crops had only 2 years (2004 and 2005) of high harvests $\left(y_{i}^{(T)} \leq+1.5 \sigma\right)$. In the year 2000, spring cereals reached the lowest yield because of the severe drought during the vegetation period. On the other hand, in 2003, winter cereals achieved the lowest yield in the Czech Republic, which was around 22\% lower in comparison to spring cereals due to an extensive winter kill. Additionally, the winter cereal was badly affected by the following early spring drought. The year 2006 also provided a relative low yield of cereals. The departures of yield of the maize, oats, and winter wheat crops were $y_{i}^{(T)} \leq-0.06$. Usually, winter wheat gives a very high yield stability in contrast to spring wheat. This fact does not work if drought occurs during November-December of the preceding year. The difference between spring and winter cereals was $23 \%$ in favor of winter cereals.

It was established that in the majority of cases, the years with highest negative yield departure $(\leq-1.5 \sigma)$ corresponding with the highest values of $S_{\mathrm{i}}-\mathrm{m} \geq 3, \mathrm{SPI} \leq-1.5$, and $r<30 \%$ suffered a severe drought. In agreement with all models for the majority of cereal crops, most of the low-yielding years were noticed at the beginning of the 1960s and 1970s and the decade of 1991-2000. Similarly, during the last 20 years, based on the $S_{\mathrm{i}}-\mathrm{m}, r$, and SPI drought indices, in nine cases of drought, four were registered as being of both a severe intensity degree and an extreme intensity degree. Since the negative values of the cereal crops yields fluctuation indicate potential adverse impacts of the agrometeorological risk, the regression analysis of the negative values of fluctuation of cereal crops yields and drought spells was carried out to clarify and estimate the expected cereal crops yields 
anomalies due to the drought risk in the Czech Republic. This suggests that the more extensive the drought areas are, the greater the fluctuation and reduction in the cereal crops yields are.

\section{Conclusions}

This paper presents the results of a study on the assessment of the drought episodes in Czechia. The methods described in this paper provide several case studies to illustrate the complex issue of drought episodes on the example of Czechia. The drought severity can also be assessed using several indices. The drought episodes were determined by three methods: according to the values of SPI, percentage of long-term precipitations $(r)$, and on the basis of the aridity index $\left(S_{\mathrm{i}}\right)$. Consequently, the combination of indices SPI, $S_{\mathrm{i}}$, and $r$ as tools in identification of severity, frequency, and extent of drought episodes have been used.

One of the main aims of this study was to present the $S_{\mathrm{i}}$ drought index and its potential use for the real time monitoring of spatial extension and severity of droughts in Czechia. $S_{\mathrm{i}}$ is usually calculated on the basis of empirical formula used to further characterize meteorological and agricultural droughts. Although the drought index requires two or three meteorological elements, it can be regarded as simple. The $S_{\mathrm{i}}$ estimates the intensity of drought events by
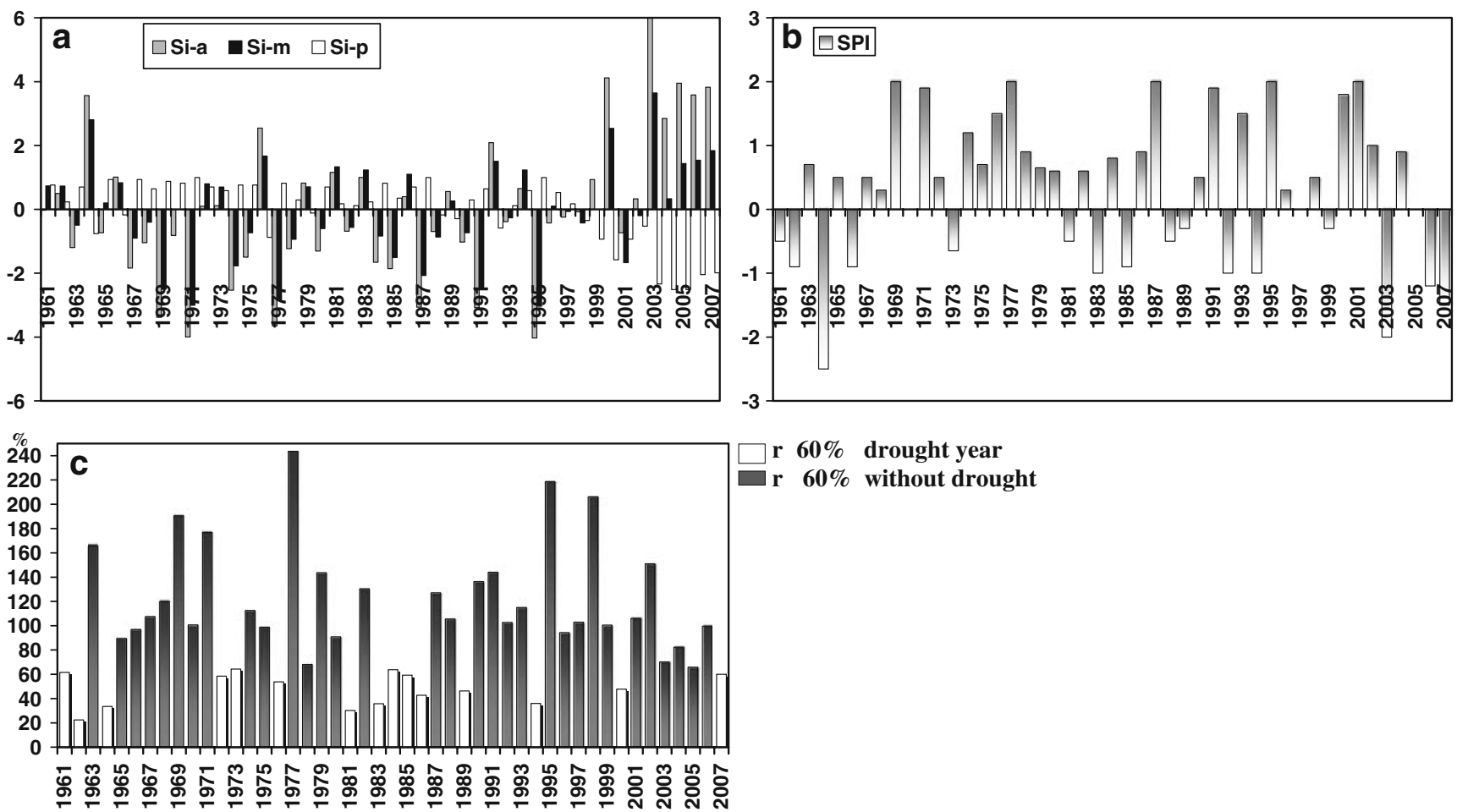

Fig. 7 Evolution of the regional severity indices values representative of the Doksany Observatory for the 47-year time series. The set of drought

indices $\left(S_{\mathrm{i}}-\mathrm{m}, S_{\mathrm{i}}-\mathrm{p}, S_{\mathrm{i}}\right.$-a, $\mathrm{SPI}$, and $\left.r\right)$ was proposed in identification of the drought severity measuring the departure of the precipitation, temperature, and moisture of the soil. Past conditions are incorporated because long-term drought is cumulative, so the intensity of drought at a particular time is dependent on the current conditions plus the cumulative patterns of the previous months. Because the $S_{\mathrm{i}}$ is normalized, wet and dry spells can be represented in the same way. A drought event occurs when the $S_{\mathrm{i}}$ continuously reaches an intensity above $0\left(S_{\mathrm{i}}>0\right)$. The event ends when the $S_{\mathrm{i}}$ becomes negative. The advantage of the $S_{\mathrm{i}}$ index is that its value can be calculated very accurately and simply because it does not contain constants or coefficients that are specific to a geographical area.

We therefore proposed to test the $S_{\mathrm{i}}$ index using the meteorological data from the territory of Czechia. The $S_{\mathrm{i}}$ index has been applied for the identification and description of droughts on the Czech territory, for the first time. As a result of the distribution in time and space of the $S_{\mathrm{i}}$ index, we have proposed new criteria for the classification of droughts. The $S_{\mathrm{i}}$ was compared with other indices, which are normally applied to this territory (e.g., SPI and $r$ ). In this study, the authors proposed testing of the three methods for calculating the $S_{\mathrm{i}}$ index: meteorological drought $\left(S_{\mathrm{i}}-\mathrm{m}\right)$, pedological drought $\left(S_{\mathrm{i}}-\mathrm{p}\right)$, and agricultural drought $\left(S_{\mathrm{i}}-\mathrm{a}\right)$.

Our evaluation of these methods showed that the more parameters are included in the $S_{\mathrm{i}}$ equation, the more precisely it determines the intensity of agricultural drought $\left(S_{\mathrm{i}}\right.$-a). A large share of the $S_{\mathrm{i}}$-a index is taken up by the soil

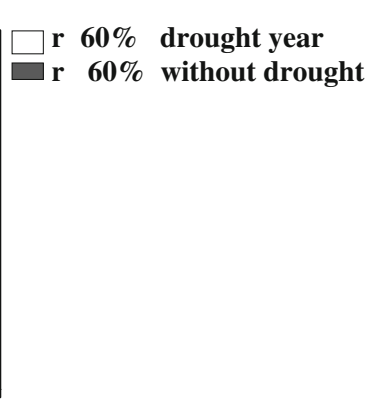

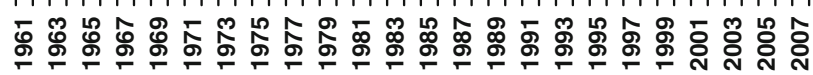


moisture parameter. This parameter can mitigate or increase the intensity of agricultural drought. $S_{\mathrm{i}}-\mathrm{p}$ pedological drought can be determined in different soil layers depending on the type of crop we wish to study.

The advantage of the complete $S_{\mathrm{i}}$ index $\left(S_{\mathrm{i}}-\mathrm{a}, S_{\mathrm{i}}-\mathrm{p}\right.$, and $\left.S_{\mathrm{i}}-\mathrm{m}\right)$ is in its ability to utilize calculations that are based on available data. Our research shows that $S_{\mathrm{i}}-\mathrm{m}$ can accurately predict a drought based on temperature and rainfall data alone. By contrast, $S_{\mathrm{i}}$-a and $S_{\mathrm{i}}$-p indices must be combined in order to predict a drought. When the $S_{\mathrm{i}}$ index as a whole is compared with the three other indices used for predicting droughts (i.e., $r$, SPI, and $\mathrm{Cm}$ ), it is clear that it works well (Fig. 7a-c). Based on the analysis of the climatic stations across Czechia, the $S_{\mathrm{i}}-\mathrm{m}$ index indicates that the territory is in the mild drought category $28 \%$ of the time, in moderate drought $14.2 \%$ of the time, in severe drought $10.4 \%$ of the time, and in extreme drought $4.8 \%$ of the time. The $S_{\mathrm{i}}$-a index is the most appropriate for measuring agricultural drought in the Czechia. Unlike the SPI and $r$ indices, which deal only with precipitation, the $S_{\mathrm{i}}-\mathrm{m}$ also contains temperature data and is, therefore, more suitable for the determination of drought conditions. There is a statistically significant relationship between the $S_{\mathrm{i}}-\mathrm{m}$ and all cereal crops $(\mathrm{Cm})$. In general, models explain a high percentage of the variability of the $\mathrm{Cm}$ due drought (more than $45 \%$ of yield variance). The result of stepwise multiple regression analysis shows that the drought was responsible for the most serious crop failures in grain production in the CR in these years: 1964, 1976, 2000, 2002, 2003, and 2006.

The contribution of the present work is mainly restricted to methodology, which allows a deeper knowledge of the characteristics of drought processes. Furthermore, it can help to decide which measures should be taken in order to prevent the problem, as it brings forward a more efficient method for the prediction of drought. Also, improved understanding of a region's drought climatology will provide critical information on the frequency and intensity of historical events.

Acknowledgments The authors gratefully acknowledge the financial support from the project MSM No. 6046070901, and thank A. Westcott for proofreading the English version. The authors would also like to thank the anonymous reviewers for a meticulous reading of the text, suggesting further style corrections, and raising critical questions.

Open Access This article is distributed under the terms of the Creative Commons Attribution Noncommercial License which permits any noncommercial use, distribution, and reproduction in any medium, provided the original author(s) and source are credited.

\section{References}

Agnew CT (2000) Using the SPI to identify drought. Drought Network News 12:6-12
Bradford RB (2000) Drought events in Europe. In: Vogt JV, Somma F (eds) Drought and drought mitigation in Europe. Advances in natural and technological hazards research, vol 14. Kluwer Academic, Norwell, pp 7-20

Brazdil R, Valasek H, Mackova J (2003) Climate in the Czech lands during the 1780s in light of the daily weather records of parson Karel Bernard Hein of Hodonice (Southwestern Moravia): comparison of documentary and instrumental data. Clim Change 60:297-327

Brazdil R, Trnka M, Dobrovolny P, Chroma K, Hlavinka P, Zalud Z (2008) Variability of droughts in the Czech Republic, 18812006. Geophys Res Abstr 10. SRef-ID: 1607-7962/gra/ EGU2008-A-03062

Brown JF, Wardlow BD, Tadesse T, Hayes MJ, Reed BC (2008) The Vegetation Drought Response Index (VegDRI): a new integrated approach for monitoring drought stress in vegetation. GIScience and Remote Sensing 45(1):16-46. doi:10.2747/1548-1603.45.1.16

Brunetti M, Maugeri M, Nanni T, Navarra A (2002) Droughts and extreme events in regional daily Italian precipitation series. Int $\mathrm{J}$ Climatol 22:543-558

Calderini D, Slafer G (1998) Changes in yield and yield stability in wheat during the 20th century. Field Crops Res 57:335-347

Chloupek O, Hrstkova P, Schweigert P (2004) Yield and its stability, crop diversity, adaptability and response to climate change, weather and fertilization over 75 years in the Czech Republic in comparison to some European countries. Field Crops Res 85:168-189

Claassen MM, Shaw RH (1970) Water deficit effects on corn. II. Grain components. Agron J 62:652-655

Craufurd PQ, Oeacock JM (1993) Effect of heat and drought stress on sorghum. II. Grain yield. Exp Agric 29:77-86

Dubrovsky M, Zalud Z, Stastna T (2000) Sensitivity of Ceres-maize yields to statistical structure of daily weather series. Clim Change 46:447-472

Dubrovsky M, Svoboda M, Trnka M, Hayes M, Wilhite DA, Zalud Z, Hlavinka P (2008) The application of relative drought indices in assessing climate change impacts on drought conditions in Czechia. Theor Appl Climatol 96:155-171. doi:10.1007/ s00704-008-0020-x

Edwards DC, McKee TB (1997) Characteristics of 20th century drought in the United States at multiple time scales. Climatology Report Number 97-2. Colorado State University, Fort Collins

FAO/WFP crop and food supply assessment mission to Moldova (2007) [http://www. fao.org./qiews/]

Hayes MJ (2003) Drought Indices. National Drought Mitigation Center, University of Nebraska-Lincoln [http://www.drought.unl. edu/whatis/indices.htm\#spi]

Heim RR (2002) A review of twentieth-century drought indices used in the United States. Bull Amer Meteor Soc 83:1149-1165

IPCC (2007) Climate change. Fourth Assessment Report of the United Nations Intergovernmental Panel. IPCC

Keyantash J, Dracup JA (2002) The quantification of drought: en evaluation of the drought indices. Bull Amer Meteor Soc 83:11671180

Kogan FN (2000) Global drought detection and impact assessment form space. In: Wilhite DA (ed) Drought: a global assessment, vol 1. Routledge, London, pp 196-210

Lana X, Burgueño A (1998) Probabilities of repeated long dry episodes based on the Poisson distribution. An example for Catalonia (NE Spain). Theor Appl Climatol 60:111-120

Liu WT, Kogan FN (1996) Monitoring regional drought using the Vegetation Condition Index. Int J Remote Sens 17:27612782

Livada I, Assimakopoulos VD (2007) Spatial and temporal analysis of drought in Greece using the Standardized Precipitation Index (SPI). Theor Appl Climatol 89:143-153 
Lloyd-Hughes B, Saunders MA (2002) A drought climatology for Europe. Int J Climatol 22:1571-1592

Loukas A, Vasiliades L (2004) Probabilistic analysis of drought spatiotemporal characteristics in Thessaly region, Greece. Nat Hazards Earth Syst Sci 4:719-731

Ped DA (1975) On indicators of droughts and wet conditions (in Russian). Proc USSR Hydrometeor Centre 156:19-39

Potop V (2003) Spatial distribution of droughts with a different degree of intensity on the territory of the Republic of Moldova. "GIS" of University "Al. I. Cuza” from Iași. nr. 9. T. XLIX, Romania, pp 145-149

Potop V, Soukup J (2008) Spatiotemporal characteristics of dryness and drought in the Republic of Moldova. Theor Appl climatol . doi:10.1007/s00704-008-0041-5

Potop V, Turkott L, Koznarova V (2008) Spatiotemporal characteristics of drought in Czechia. Sci Agric Bohem 39(3):258-268

Rossi G, Cancelliere A, Pereira LS, Oweis T, Shatanawi M, Zairi A (2003) Tools for Drought Mitigation in Mediterranean Regions. Springer, New York 9781402011405, p 357 ISBN 1402011407

Sonnett J, Morehouseb BJ, Fingerc TD, Garfind G, Rattraye N (2006) Drought and declining reservoirs: comparing media discourse in Arizona and New Mexico, 2002-2004. Glob Environ Change 16:95-113

Svoboda M, Lecomte D, Hayes M, Heim R, Gleason K, Angel J, Rippey B, Tinker R, Palecki M, Stooksbury D, Miskus D, Stephens S (2002) The drought monitor. Bull Am Meteorol Soc 83:1181-1190

Tolasz R, Brázdil R, Bulír O, Dobrovolný P, Dubrovský M, Hájková L, Halásová O, Hostýnek J, Janouch M, Kohut M, Krška K, Křivancová S, Květoň V, Lepka Z, Lipina P, Macková J, Metelka L, Míková T, Mrkvica, Možný M, Nekovař J, Němec L, Pokorný J, Reitschlager JD, Richterová D, Rožnovský J, Řepka M, Semeradová D, Sosna V, Stř́̌̌z M, Šerlc P, Škáchová H, Štěpánek P, 3tepánková P, Trnka M, Valeriánová A, Valter J, Vaníček K, Vavruška F, Voženílek V, Vrábík T, Vysoudil M, Zahradníček J, Zusková I, Žák M, Žalud Z (2007) Climate Atlas of Czechia.
Czech Hydrometeorological Institute, Prague, p 254. ISBN 97880-86690-1

Trnka M, Hlavinka P, Semeradova D, Dubrovsky M, Zalud Z, Mozny M (2007) Agricultural drought and spring barley yields in the Czech Republic. Plant Soil Environ 53(2007):306-316

Trnka M, Dubrovsky M, Svoboda MD, Semeradova D, Hayes MJ, Zalud Z, Wilhite DA (2009) Developing a regional drought climatology for the Czech Republic for 1961-2000. Int J Climatol 29:863-883

Unganai LS, Kogan FN (1998) Drought monitoring and corn yield estimation in Southern Africa from AVHRR data. Rem Sens Environ 63:219-232

van Lanen HAJ, Peters E (2000) Definition, effects and assessment of groundwater droughts. In: Vogt JV, Somma F (eds) Drought and drought mitigation in Europe. Kluwer Academic, Dordrecht, pp 49-61

Vicente-Serrano SM, Cuadrat-Prats JM (2007) Trends in drought intensity and variability in the middle Ebro valley (NE of the Iberian peninsula) during the second half of the twentieth century. Theor Appl Climatol 88:247-258

Wilhelmi OV, Hubbard KG, Wilhite DA (2002) Agroclimatological factors influencing vulnerability to agricultural drought: a Nebraska case study. Int J Climatol 22:1399-1414

Wilhite DA (1990) The enigma of drought: management and policy issues for the 1990s. Int J Environ Stud 36:41-54

Wilhite DA (2000) Drought as a natural hazard: concepts and definitions. In: Wilhite DA (ed) Drought: a global assessment, natural hazards and disasters series. Routledge, London, pp 3 18

Wilhite DA, Svoboda MD (2000) Drought early warning systems in the context of drought preparedness and mitigation. In: Wilhite DA, Sivakumar MVK, Wood DA (eds) Early warning systems for drought preparedness and drought management. World Meteorological Organization, Lisboa, pp 1-21

Wu H, Wilhite DA (2004) An operational agricultural drought risk assessment model for Nebraska, USA. Nat Hazards 33:1-21 